PAPER • OPEN ACCESS

Biocompatibility and degradation of the open-pored magnesium scaffolds LAE442 and La2

To cite this article: N Kleer-Reiter et al 2021 Biomed. Mater. 16035037

View the article online for updates and enhancements. 


\title{
Biomedical Materials
}

\section{PAPER}

CrossMark

OPEN ACCESS

RECEIVED

7 July 2020

REVISED

17 March 2021

ACCEPTED FOR PUBLICATION

7 April 2021

PUBLISHED

21 April 2021

Original content from

this work may be used

under the terms of the

Creative Commons

Attribution 4.0 licence.

Any further distribution

of this work must

maintain attribution to

the author(s) and the title

of the work, journal

citation and DOI.

\section{Biocompatibility and degradation of the open-pored magnesium scaffolds LAE442 and La2}

\author{
N Kleer-Reiter ${ }^{1}$ (D, S Julmi², F Feichtner 1 , A-C Waselau ${ }^{1}$, C Klose 2 , P Wriggers ${ }^{3}$, H J Maier ${ }^{2}$ \\ and $A$ Meyer-Lindenberg ${ }^{1, *}$ \\ 1 Clinic of Small Animal Surgery and Reproduction, Ludwig-Maximilians-Universität, Veterinärstr. 13, München 80539, Germany \\ 2 Institut für Werkstoffkunde (Materials Science), Leibniz Universität Hannover, An der Universität 2, Garbsen 30823, Germany \\ 3 Institute of Continuum Mechanics, Leibniz Universität Hannover, Appelstr. 11, Hannover 30167, Germany \\ * Author to whom any correspondence should be addressed. \\ E-mail: ameylin@lmu.de
}

Keywords: magnesium alloy, porous scaffold, $\mu \mathrm{CT}$, biocompatibility, osseointegration

\begin{abstract}
Porous magnesium implants are of particular interest for application as resorbable bone substitutes, due to their mechanical strength and a Young's modulus similar to bone. The objective of the present study was to compare the biocompatibility, bone and tissue ingrowth, and the degradation behaviour of scaffolds made from the magnesium alloys LAE442 $(n=40)$ and Mg-La2 $(n=40)$ in vivo. For this purpose, cylindrical magnesium scaffolds (diameter $4 \mathrm{~mm}$, length $5 \mathrm{~mm}$ ) with defined, interconnecting pores were produced by investment casting and coated with $\mathrm{MgF}_{2}$. The scaffolds were inserted into the cancellous part of the greater trochanter ossis femoris of rabbits. After implantation periods of 6, 12, 24 and 36 weeks, the bone-scaffold compounds were evaluated using ex vivo $\mu \mathrm{CT} 80$ images, histological examinations and energy dispersive $\mathrm{x}$-ray spectroscopy analysis. The La2 scaffolds showed inhomogeneous and rapid degradation, with inferior osseointegration as compared to LAE442. For the early observation times, no bone and tissue could be observed in the pores of La2. Furthermore, the excessive amount of foreign body cells and fibrous capsule formation indicates insufficient biocompatibility of the La2 scaffolds. In contrast, the LAE442 scaffolds showed slow degradation and better osseointegration. Good vascularization, a moderate cellular response, bone and osteoid-like bone matrix at all implantation periods were observed in the pores of LAE442. In summary, porous LAE442 showed promise as a degradable scaffold for bone defect repair, based on its degradation behaviour and biocompatibility. However, further studies are needed to show it would have the necessary mechanical properties required over time for weight-bearing bone defects.
\end{abstract}

\section{Introduction}

Currently, the treatment of large bone defects caused by trauma, infection or tumour constitute a serious medical problem, especially when defects of critical size lack the ability to heal and impaired bone healing occurs $[1,2]$. Although autografts are the gold standard for the treatment of these defects, they are associated with the problems of limited availability, additional surgery and postoperative complications $[3,4]$. For this reason, there is a great demand in orthopaedic surgery for alternatives to bone grafts for bone defects. Although the use of porous ceramics and polymers as degradable bone substitutes were some of the first implantable biomaterials, the use of degradable porous metals has become a focus of research in recent years [5-7].

Degradable bone substitutes should preferably have an osteoinductive and osteoconductive effect, as well as a good long-term biocompatibility and a degradation rate adapted to the formation of new bone $[4,5]$. For successful osseointegration of scaffolds, certain structural properties such as high porosity, suitable pore size, and interconnecting pores are of particular importance $[4,8,9]$. The pores have a great influence on the immigration and ingrowth of cells and blood vessels, as well as for ensuring the nutritive supply to the ingrowing tissue. Scaffolds 
with macropores between 150 and $500 \mu \mathrm{m}$ proved to be particularly advantageous $[5,10,11]$.

In addition, although it depends on the application and the stabilization technique, the bone substitutes should have similar mechanical properties to bone, both in the area of the defect and at the attachment to the surrounding bone. Current porous bone substitutes made of polymers or ceramics, such as $\beta$-tricalcium phosphate (TCP), can show good biocompatibility and osseointegration, but have low mechanical stability, so they are mainly used to fill smaller defects or are applied as coatings [12, 13]. For effective treatment of long tubular bone defects, cylindrical titanium mesh cages combined with a bone graft have been used to repair critical size bone defects $[14,15]$. However, removal of the inserted titanium mesh cage is not possible after it has been surrounded by bone. Therefore, leaving the titanium mesh cages in the bone may result in stress shielding, secondary bone absorption and fracture $[14,16]$.

The resorbable metal magnesium and its alloys have been investigated in numerous studies for orthopaedic use due to the positive properties in context with biomedical application $[13,17,18]$. Among these positive properties are a Young's modulus similar to bone $[16,17]$ and a significantly higher mechanical stability compared to polymers and ceramics [13]. Furthermore, magnesium is an essential element in the body and is involved in many metabolic and enzymatic reactions [19]. However, the comparatively rapid degradation and the associated accumulation of hydrogen and corrosion products in aqueous solution are the main disadvantages of magnesiumbased implants [13, 20, 21].

So far, most magnesium alloys have only been investigated as solid implants with a comparably small surface area available for corrosion. Thus, the interaction with the host tissue and the bone to scaffold interface could only be assessed to a limited extent. In contrast, open porous implants provide a larger surface area that can enhance osseointegration, but also increase the degradation rate. Therefore, these scaffolds should consist of slowly degrading magnesium alloys to ensure sufficient mechanical stability when used as a bone substitute [7]. In order to control and reduce the rapid degradation, the resistance of magnesium alloys can be tailored by selecting appropriate alloying elements. Alloys containing the elements aluminium $(\mathrm{Al})$, lithium $(\mathrm{Li})$, zinc and rare earths (REs) have proven to be particularly resistant $[22,23]$. Screws made of the magnesium alloy MgYREZr (MAGNEZIX ${ }^{\circledR}$ ) are already used in human medicine $[24,25]$.

The magnesium alloy LAE442 contains $\mathrm{Li}, \mathrm{Al}$ and RE as alloying elements and has proven to be very resistant and biocompatible in many in vitro and in vivo studies in the form of intramedullary pins, cylindrical solid bodies and screw-plate systems [26-31]. The binary alloy Mg-La2 with lanthanum, on the other hand, has only been tested in vitro so far and has demonstrated an improved reproducibility by using fewer alloy components [32]. In the study by Weizbauer et al, the alloy showed good cell compatibility and good material properties for in vivo evaluation [32].

In addition, many studies have shown that coatings or surface treatments of magnesium implants have a corrosion retarding effect $[33,34]$. Coating with $\mathrm{MgF}_{2}$ showed a significant reduction in magnesium degradation in the initial phase, and direct contact to the surrounding bone $[35,36]$. Furthermore, better attachment and proliferation of cells could be achieved on $\mathrm{MgF}_{2}$-coated magnesium implants compared to uncoated ones [37]. Compared to microarc oxidation and other surface treatments, $\mathrm{MgF}_{2}$ coating is a simple and cost-effective method suitable for industrial production [38].

The production of reproducible, porous magnesium scaffolds can be a challenge, since most manufacturing techniques, such as powder metallurgy technology, only achieve undefined pore structures $[6,7,39,40]$. However, with the investment casting process it is possible to obtain defined interconnecting pore structures of $\mathrm{Mg}$-based scaffolds with a high design flexibility [41].

Using this method, porous scaffolds made of the alloys LAE442 and Mg-La2 were produced and investigated by Julmi et al [42]. The in vitro tests showed sufficient strength of the scaffolds to withstand the forces in rabbit bone with a compression weight-bearing capacity 3.4 times (La2) and 5.6 times (LAE442) higher than the expected load $[41,42]$. In the in vivo study by Kleer et al the two magnesium scaffolds LAE442 and La2 with defined interconnecting pores and $\mathrm{MgF}_{2}$ coating were evaluated using regular radiological and in vivo $\mu \mathrm{CT}$ images over a period of 36 weeks [43]. In this study, slow degradation behaviour for the LAE442 scaffolds and comparatively fast degradation of the La2 scaffolds with higher gas production could already be observed.

The objective of this study was to compare the biocompatibility and the degradation mechanisms of the porous magnesium scaffolds made of the alloys LAE442 and Mg-La2 using high-resolution $\mu \mathrm{CT} 80$ images, histological examinations and SEM/energy dispersive $\mathrm{x}$-ray spectroscopy (EDX) analyses after an implantation period of up to 36 weeks.

\section{Materials and methods}

\subsection{Scaffolds}

For the present study, 80 cylindrical scaffolds (ø $4 \mathrm{~mm}$, length $5 \mathrm{~mm}$ ), each with interconnecting pores (max. pore size $500 \mu \mathrm{m}$, porosity $41.4 \%$ ), were produced from the magnesium alloys La2 $(n=40$; 2 wt. $\%$ La) and LAE442 ( $n=40 ; 4$ wt.\% Li, 4 wt.\% Al, 2 wt.\% REs) by investment casting [41]. The scaffolds were coated with $\mathrm{MgF}_{2}$ using the conversion coating 


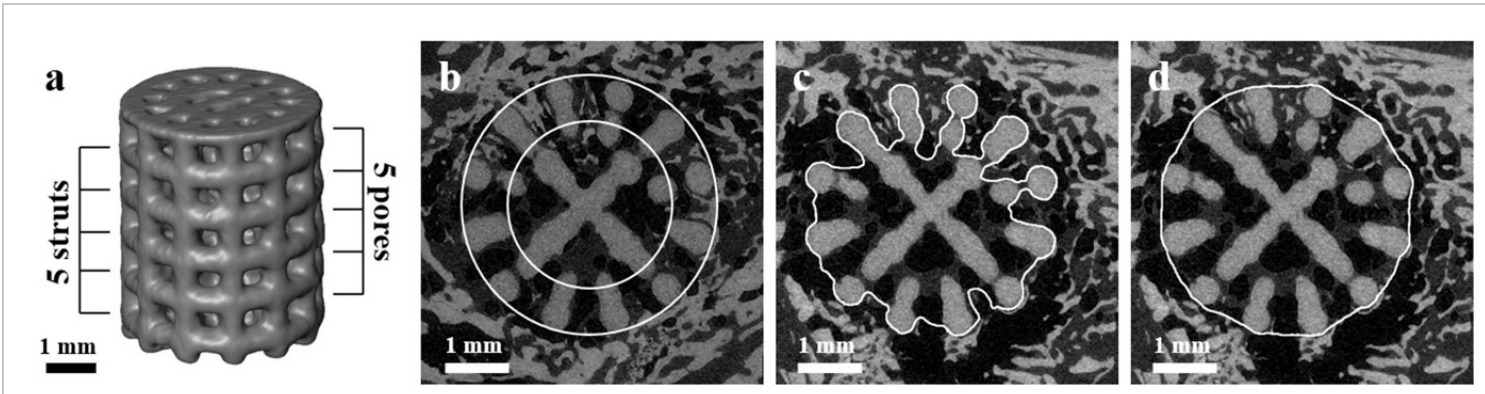

Figure 1. (a) Geometry of the scaffolds featuring five pores and five struts and (b) cross-section with outer and inner ring for semi-quantitative analysis; (c) basic contour and (d) extended contour for quantitative analysis of $\mu$ CT80 scans.

method (thickness between 450 and $1250 \mathrm{~nm}$ ) and sterilized by gamma radiation ( $>25 \mathrm{kGy}$, BBF Sterilisation Service GmbH, Kernen, Germany). The production process and the $\mathrm{MgF}_{2}$ coating of the scaffolds is described in more detail in the literature [41]. A total of 40 commercially available, porous $\beta$-TCP implants (Cerasorb ${ }^{\circledR} \mathrm{M}$, Curasan AG, Kleinostheim, Germany) with the same dimensions ( $\varnothing 4 \mathrm{~mm}$, length $5 \mathrm{~mm}$, total porosity $65 \%$ ) served as a control group.

\subsection{Animal model}

The animal experiment was approved by the government of Upper Bavaria according to the Animal Welfare Act (approval number: 55.2-1-54-2532181-2015). A total of 60 mature female Zika rabbits (Asamhof, Kissing, Germany; $\varnothing$ weight: $3.96 \pm 0.27 \mathrm{~kg}$, age: $>6$ months) were allocated to time groups of $6,12,24$ and 36 weeks. For each time group, ten scaffolds of both magnesium alloys and the TCP control group were randomly inserted into the cancellous part of the trochanter major ossis femoris of the rabbits. Using a $4 \mathrm{~mm}$ drill, an approximately $6 \mathrm{~mm}$ deep hole was drilled into the cancellous part of the greater trochanter and the scaffolds were inserted. The exact course of the surgical procedure, as well as anaesthesia and postoperative care, are described elsewhere [43]. After the respective implantation periods, the animals were sedated with ketamine $\left(15 \mathrm{mg} \mathrm{kg}^{-1}\right.$, Anesektin ${ }^{\circledR}$, Albrecht $\mathrm{GmbH}$, Aulendorf, Germany) and medetomidine $\left(0.25 \mathrm{mg} \mathrm{kg}^{-1}\right.$, Dorbene vet ${ }^{\circledR}$, Zoetis Deutschland $\mathrm{GmbH}$, Berlin, Germany), and euthanized by intravenous application of pentobarbital $\left(182.3 \mathrm{mg} \mathrm{kg}^{-1}\right.$, Narkodorm ${ }^{\circledR}, \quad$ CP-Pharma GmbH, Burgdorf, Germany) for the ex vivo examinations.

\subsection{Ex vivo $\mu \mathrm{CT}$}

Both femora were explanted, and all soft tissue was removed to harvest the implantation sites with a diamond band saw (Cut-grinder, patho-service $\mathrm{GmbH}$, Oststeinbek, Germany). For the following investigations, the bone-scaffold compounds were fixed in a $4 \%$ formaldehyde solution for at least 14 days and positioned upright in plastic tubes fixed with foam sponges. Subsequently, ex vivo $\mu \mathrm{CT}$ scans of the bone-scaffold compounds were performed with a $\mu$ CT80 (Scanco Medical AG, Brüttisellen, Switzerland). The scan settings were: $600 \mathrm{~ms}, 70 \mathrm{kVp}$ and $114 \mu \mathrm{A}$ with a resolution of $10 \mu \mathrm{m}$. The scaffolds were manually contoured in the original scans and reoriented (Software $\mu$ CT Evaluation Program V6.6, Scanco Medical, Zurich, Switzerland) to improve the comparability as the cross-sections allowed better assessment of the scaffolds with their immediate surroundings. In order to determine the degradation of the magnesium scaffolds, scans were performed before implantation with the same scan settings and compared with the ex vivo scans.

\subsubsection{Semi-quantitative analysis}

A semi-quantitative scoring system modified according to Lalk et al was used to evaluate the $\mu$ CT80 images of all scaffolds [44]. The parameters scaffold degradation and scaffold shape, as well as the parameters gas within and in the direct surroundings of the scaffolds were evaluated. In addition, the structure of the surrounding cancellous bone was assessed in two areas of the scaffolds (upper and lower half of the scaffold). The integration of scaffold into bone (bone-to-scaffold contact) was evaluated on ten cross-sections (five pore and five strut levels each; $\mathrm{cf}$ figure 1(a)). Based on these cross-sections, the bone within the scaffolds was evaluated in an outer and an inner ring (figure 1(b)). For the TCP control group, the parameters degradation and scaffold shape were not examined due to different material properties. Score values ranged from 0 for physiological/original to 4 for clearly altered (table 1 ).

\subsubsection{Quantitative analysis}

A threshold (LAE442 160, La2 186, TCP 360) was determined for each material group and applied for the subsequent evaluations. In order to calculate the volume, density and surface area of the scaffolds after the respective implantation period of $6,12,24$ or 36 weeks, the residual scaffolds in the reoriented scans were manually contoured by excluding the ingrown bone (basic contour; figure $1(\mathrm{c})$ ). This analysis was also performed for the magnesium scaffolds before implantation to obtain the baseline values. 
Table 1. Scoring system for semi-quantitative $\mu$ CT80 evaluation, modified according to Lalk et al [36].

\begin{tabular}{|c|c|c|c|c|c|}
\hline Parameters & Score 0 & Score 1 & Score 2 & Score 3 & Score 4 \\
\hline Degradation & Not observed & $\begin{array}{l}\text { Thin degradation } \\
\text { layer }\end{array}$ & $\begin{array}{l}\text { Clear degradation } \\
\text { layer }\end{array}$ & $\begin{array}{l}>50 \% \text { of scaffold } \\
\text { degraded }\end{array}$ & $\begin{array}{l}\text { Complete } \\
\text { degradation }\end{array}$ \\
\hline Shape of scaffold & Original & $\begin{array}{l}\text { Slight changes on } \\
\text { surface }\end{array}$ & $\begin{array}{l}\text { Small portions } \\
\text { detached }\end{array}$ & $\begin{array}{l}\text { Large scaffold } \\
\text { parts detached, } \\
>50 \% \text { altered }\end{array}$ & $\begin{array}{l}\text { Complete loss of } \\
\text { shape }\end{array}$ \\
\hline $\begin{array}{l}\text { Gas } \\
\text { within/directly } \\
\text { around scaffold }\end{array}$ & Not observed & $\begin{array}{l}\text { Diffuse and few } \\
\text { small bubbles }\end{array}$ & $\begin{array}{l}>25 \% \text { pores } \\
\text { or surface } \\
\text { filled/covered }\end{array}$ & $\begin{array}{l}>50 \% \text { pores } \\
\text { or surface } \\
\text { filled/covered }\end{array}$ & $\begin{array}{l}\text { Pores/surface } \\
\text { completely } \\
\text { filled/covered }\end{array}$ \\
\hline $\begin{array}{l}\text { Structure of } \\
\text { cancellous bone } \\
\text { in vicinity }\end{array}$ & $\begin{array}{l}\text { Physiologically } \\
\text { wide-meshed }\end{array}$ & $\begin{array}{l}\text { Thick }(>100 \mu \mathrm{m}) \\
\text { and thin } \\
(<100 \mu \mathrm{m}) \\
\text { trabeculae }\end{array}$ & $\begin{array}{l}\text { Narrow-meshed } \\
\text { (on average } \\
50 \mu \mathrm{m}) \text { with } \\
\text { occasional thick } \\
(>100 \mu \mathrm{m}) \\
\text { trabeculae }\end{array}$ & $\begin{array}{l}\text { Small bone } \\
\text { particles }\end{array}$ & No bone \\
\hline $\begin{array}{l}\text { Integration of } \\
\text { scaffold into bone }\end{array}$ & $\begin{array}{l}\text { Broad contact } \\
\text { area to adjacent } \\
\text { cancellous bone } \\
\text { through many } \\
\text { trabeculae, } \\
\text { no/only fractional } \\
\text { gap }\end{array}$ & $\begin{array}{l}\text { Contact to } \\
\text { adjacent } \\
\text { cancellous bone } \\
\text { through several } \\
\text { trabeculae, } \\
\text { sporadic gaps }\end{array}$ & $\begin{array}{l}\text { Contact to } \\
\text { adjacent } \\
\text { cancellous bone } \\
\text { through few } \\
\text { trabeculae, clear } \\
\text { gaps }\end{array}$ & $\begin{array}{l}\text { One contact } \\
\text { to adjacent } \\
\text { cancellous bone, } \\
\text { manifest gaps }\end{array}$ & $\begin{array}{l}\text { No contact } \\
\text { to adjacent } \\
\text { cancellous bone, } \\
\text { manifest gap }\end{array}$ \\
\hline $\begin{array}{l}\text { Bone within } \\
\text { scaffold } \\
\text { outer/inner ring }\end{array}$ & $\begin{array}{l}>10 \% \text { of pores } \\
\text { with bone }\end{array}$ & $\begin{array}{l}6 \%-10 \% \text { of pores } \\
\text { with bone }\end{array}$ & $\begin{array}{l}2 \%-5 \% \text { of pores } \\
\text { with bone }\end{array}$ & $\begin{array}{l}1 \% \text { of pores with } \\
\text { bone }\end{array}$ & No bone \\
\hline
\end{tabular}

In order to determine the amount of bone inside the scaffolds, an extended contour was created based on the exact scaffold rims (figure 1(d)). Therefore, the difference between the extended and the basic contour was defined as ingrown bone.

A total of seven scaffolds per material and time group were quantitatively investigated. The analyses were performed using $\mu \mathrm{CT} 80$ scans if scaffold material could be detected and contoured. Otherwise, the scans were assessed descriptively.

\subsection{Histological examination}

The bone-scaffold compounds were removed from the $4 \%$ buffered formaldehyde solution and were dehydrated in a series of increasingly concentrated alcohol solutions, ending in $100 \%$. Subsequently, xylene served as the intermedium before the samples were embedded in a plastic resin based on methyl methacrylate (Technovit ${ }^{\circledR}$ 9100, Heraeus Kulzer, Wehrheim, Germany). Using the cutting and grinding technique according to Donath, cross-sections of $70 \mu \mathrm{m}$ thickness were produced [45]. A central cross-section (level with pores not struts) of each bone-scaffold compound was then stained with toluidine blue O (Waldeck, Münster, Germany) [46]. The histological examinations were performed using a Zeiss Axio Imager 2 microscope (Carl Zeiss Microscopy GmbH, Jena, Germany) and Zeiss ZEN2 software (Carl Zeiss Microscopy, Jena, Germany). The samples were assessed semi-quantitatively using a scoring system, whereby score values between 0 and 3 were assigned for all parameters (table 2).

At $25 \times$ magnification, a circle with a $4 \mathrm{~mm}$ diameter was placed around the scaffolds and the amount of scaffold material (total/cracked), bone, non-mineralized bone matrix, granulation tissue and gas were examined (figure 2). Furthermore, the parameters resorption of bone and fibrous capsule formation in the immediate vicinity of the scaffolds were assessed. For the evaluation of gas bubbles, the presence of thin fibrocyte borders was investigated to distinguish between bubbles formed in vivo by degradation and those formed by the preparation process.

Blood vessels and cells (fibrocytes, macrophages, foreign body cells (FBCs), neutrophil granulocytes and lymphocytes) were examined at $100 \times$ magnification in four areas: within a central, medial and peripheral ring in the scaffold, and direct scaffold vicinity (figure 2).

\subsection{SEM/EDX}

The in vitro and ex vivo degradation behaviour of the two scaffolds LAE442 and La2 was already comparatively investigated using SEM and EDX analysis in an earlier study [2]. Based on these results and the histological results from the present study, selected SEM and EDX analyses were performed with a SUPRA 55 VP (Carl Zeiss AG, Oberkochen, Germany) to investigate areas of special interest (degradation layer, $\mathrm{MgF}_{2}$ coating, bone-to-scaffold contact, cell clusters). An acceleration voltage of $15 \mathrm{kV}$ and a working distance 
Table 2. Scoring system for the histological evaluation of the bone-scaffold compound cross-sections.

\begin{tabular}{|c|c|c|c|c|}
\hline Parameters & Score 0 & Score 1 & Score 2 & Score 3 \\
\hline $\begin{array}{l}\text { Scaffold material } \\
\text { Cracks } \\
\text { Gas within/adjacent } \\
\text { Bone resorption }\end{array}$ & $0 \%$ & $1 \%-25 \%$ & $26 \%-50 \%$ & $>50 \%$ \\
\hline $\begin{array}{l}\text { Bone } \\
\text { Non-mineralized } \\
\text { bone matrix } \\
\text { Granulation tissue }\end{array}$ & $0 \%$ & $1 \%-10 \%$ & $11 \%-25 \%$ & $>25 \%$ \\
\hline $\begin{array}{l}\text { Fibrous capsule } \\
\text { Fibrous cells (tissue) } \\
\text { Vascularization } \\
\text { (blood vessels) }\end{array}$ & $\begin{array}{l}\text { None } \\
\text { None }\end{array}$ & $\begin{array}{l}\text { Mild } \\
\text { Few }\end{array}$ & $\begin{array}{l}\text { Moderate } \\
\text { Moderate }\end{array}$ & $\begin{array}{l}\text { Severe } \\
\text { Many }\end{array}$ \\
\hline $\begin{array}{l}\text { Macrophages } \\
\text { FBCs } \\
\text { Lymphocytes } \\
\text { Neutrophil } \\
\text { granulocytes }\end{array}$ & None & Few & Moderate & Many \\
\hline
\end{tabular}

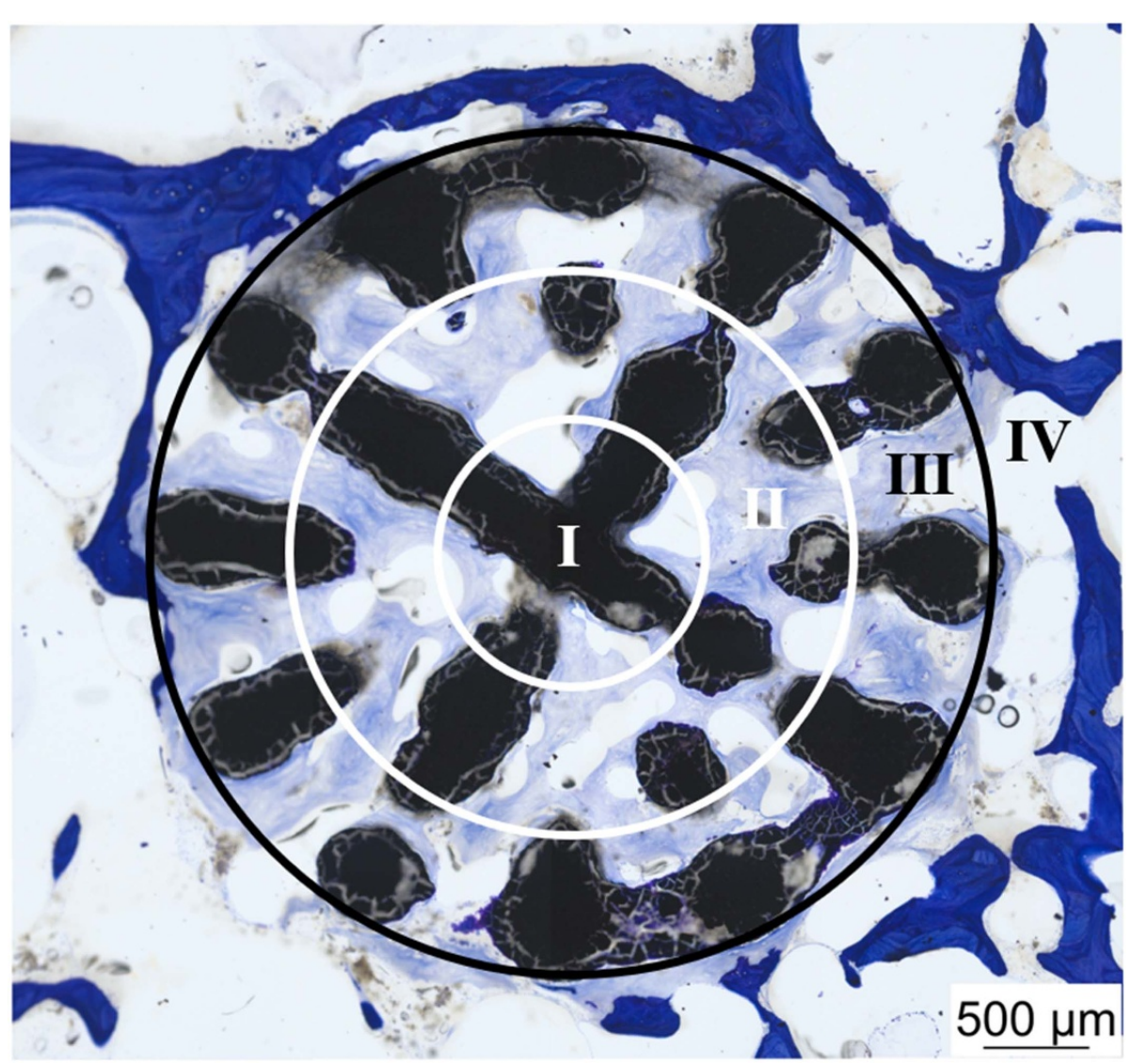

Figure 2. Histological image of scaffold cross-section; evaluation at $25 \times$ magnification, subdivided in two areas: inside and outside black circle $(4 \mathrm{~mm})$; evaluation at $100 \times$ magnification, subdivided in four areas: central ring (I), medial ring (II) and peripheral ring (III), and direct scaffold vicinity (IV).

of 20-25 $\mathrm{mm}$ for the overview images and 7.8-9.8 $\mathrm{mm}$ for the close-up images were used. Carbon and oxygen were excluded, as it is difficult to quantify their amount by EDX analysis.

\subsection{Statistics}

The data were statistically evaluated using SPSS Statistics 25.0. Since the data were not normally distributed, Kruskal-Wallis tests were used for the evaluation and a pairwise comparison was performed with subsequent single-functional ANOVA. Subsequently, adjustments were made using the Bonferroni correction. Quantitative data on the degradation of the magnesium scaffolds were investigated using the Mann-Whitney U-test. In all analyses, a value of $p<0.05$ was considered significant. 

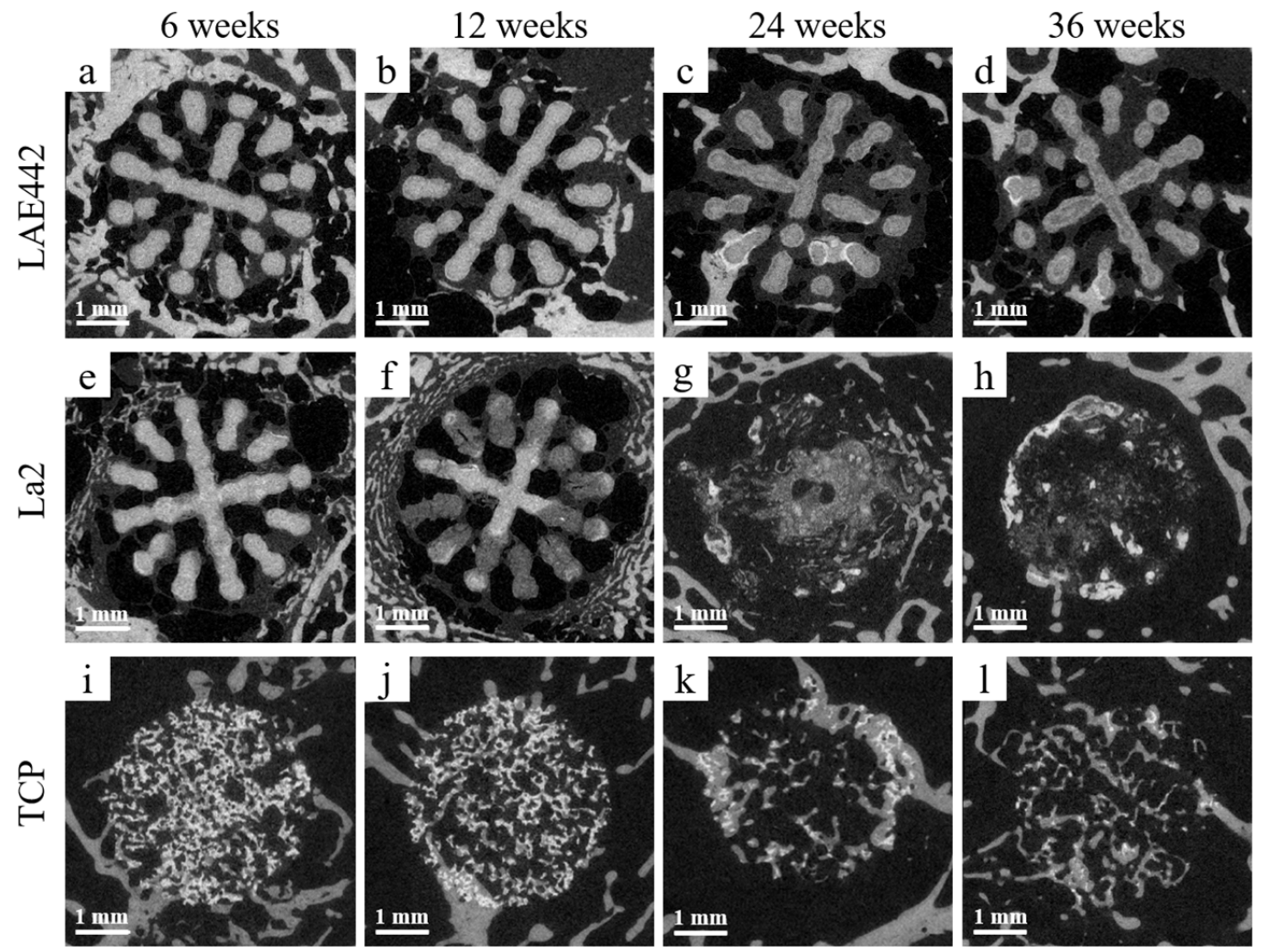

Figure 3. $\mu \mathrm{CT} 80$ images of cross-sections; progression of degradation of the scaffolds after implantation periods of $6,12,24$ or 36 weeks; (a)-(d) LAE442, (e)-(h) La2 and (i)-(l) TCP.

\section{Results}

\subsection{Ex vivo $\mu \mathrm{CT}$}

\subsubsection{Semi-quantitative $\mu$ CT80 evaluations}

Using $\mu \mathrm{CT} 80$ images, the exact degradation behaviour of the scaffolds as well as the ingrowth of bone into the scaffolds were assessed (figure 3).

The LAE442 scaffolds showed an overall very slow and homogeneous degradation. After 6 and 12 weeks, only a thin degradation layer (score 1 ) was detected at the edge of the scaffolds. The scaffold shape remained unchanged (score 1) after 6 weeks and only slight surface changes (score 1) occurred after 12 weeks of implantation. After 24 and 36 weeks, all LAE442 (with one exception, week 24, score 1) showed a clearly recognizable degradation layer with small, detached parts of the scaffolds (score 2). Bright inhomogeneous areas could be observed after 6 weeks on the LAE442 scaffolds (figure 4(a)), which increased strongly in size and number until week 36 . In contrast, the La2 scaffolds showed rapid and inhomogeneous degradation. After 6 weeks, a clear degradation layer (score 2) was visible with detachment of increased small and occasionally large scaffold particles (score 2 and 3). A single La2 scaffold was already completely degraded (score 4). More than $50 \%$ of the La2 scaffolds were degraded after 12 weeks (score 3; with one exception, score 2), and large portions of the scaffolds were separated (score 3 ). From 24 weeks onwards, all La2 scaffolds (with one exception, week 24, score 3) were completely degraded and the shape of the scaffold was no longer recognizable (score 4). Overall, the La2 scaffolds showed significantly faster degradation and loss of shape in all week groups compared to the LAE442 scaffolds $(p<0.001)$.

In contrast to the TCP control group, accumulation of gas could be detected in the scaffolds made from the two magnesium alloys. The highest accumulation of gas was found in La2 after 12 weeks. More than $50 \%$ of the internal space (pores) was filled with gas and more than $50 \%$ of the direct surface was surrounded by gas. Subsequently, at week 24 only small amounts of gas were observed and at week 36 no gas was found. In contrast, LAE442 showed a relatively constant gas accumulation directly around the scaffolds, which covered at least $25 \%$ and sometimes more than $50 \%$ of the surface, over all observation times. Within the LAE442 scaffolds, more than 25\% and up to $50 \%$ of the interstices were filled at the early implantation points, and mainly small gas bubbles were observed at the later implantation points.

In all time groups, bone in the vicinity of the LAE442 scaffolds mainly showed a mixture of thick and thin trabeculae, which was more pronounced in the upper half of the scaffolds near the drill hole (figure 5(a)). In the lower part near the medullary 

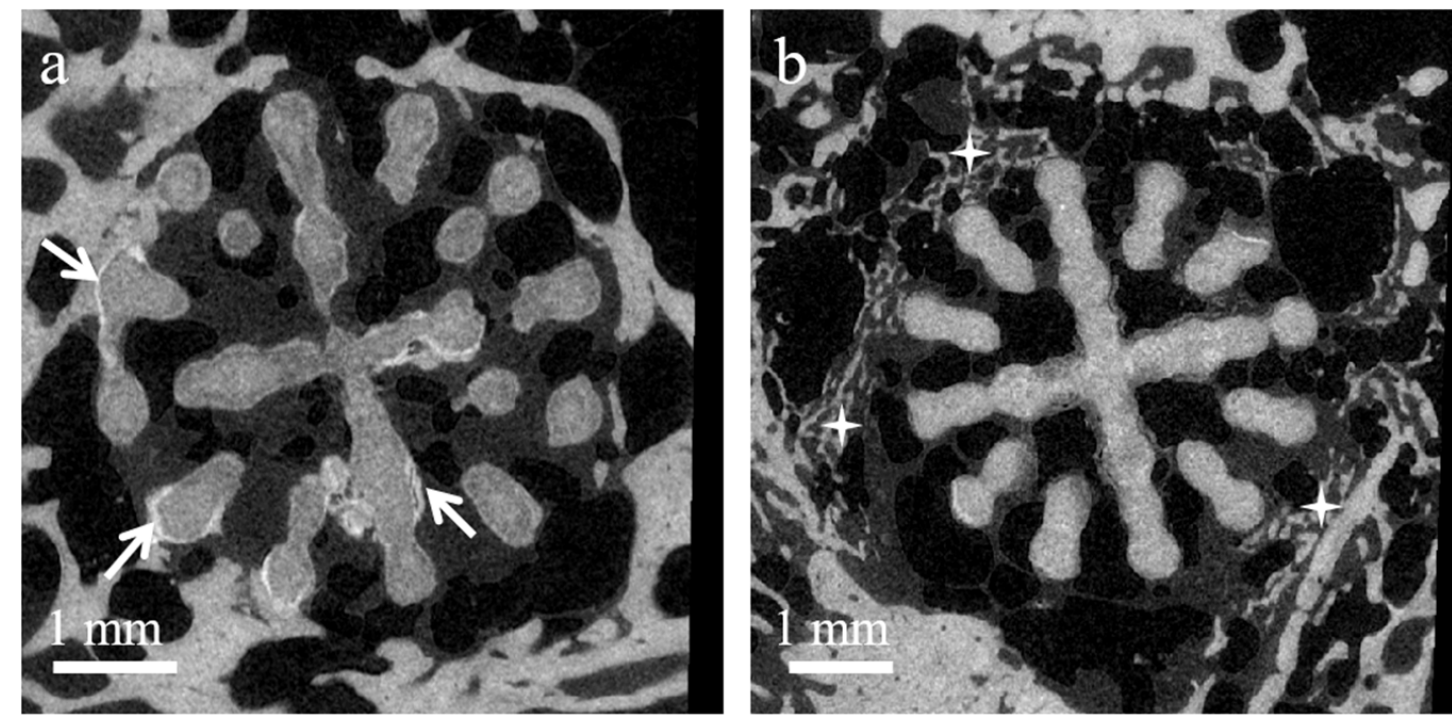

Figure 4. $\mu$ CT80 images: (a) LAE442 scaffold 36 weeks after implantation, arrow: bright appearing deposits (Ca/P) on scaffold surface; (b) La2 scaffold 6 weeks after implantation, star: narrow-meshed bone trabeculae.

a Structure of surrounding bone

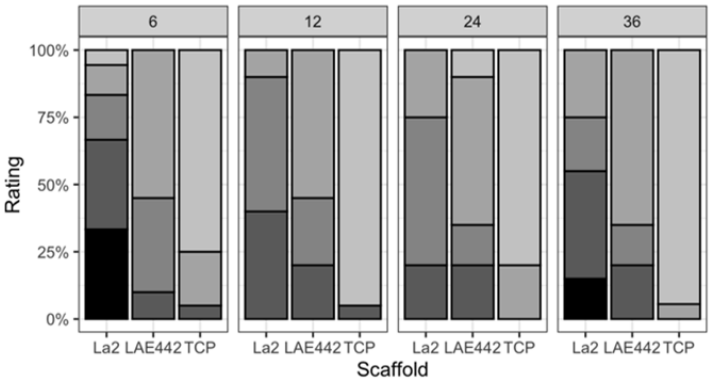

$\mathrm{C}$

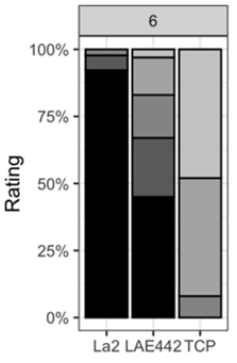

Bone outer ring

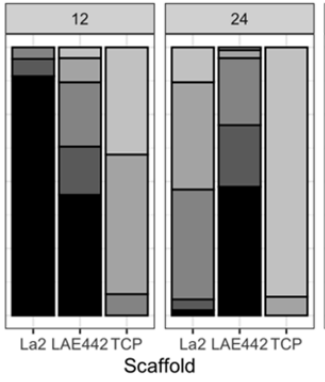

Score

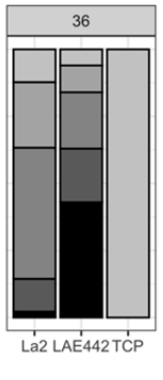

b Scaffold integration into bone
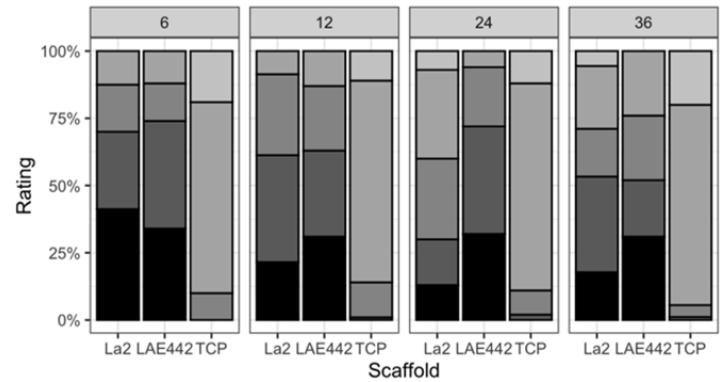

d

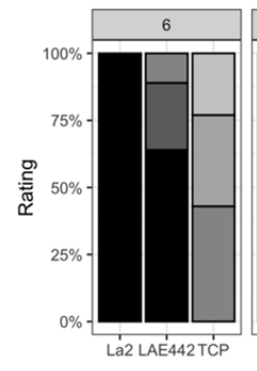

Bone inner ring
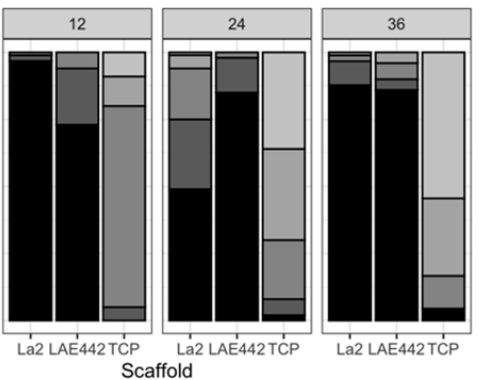

$2 \square 3 \square 4$

Figure 5. Semi-quantitative analysis of the $\mu \mathrm{CT} 80$ scans showing the parameters after the implantation periods of $6,12,24$ and 36 weeks: (a) structure of surrounding bone, (b) scaffold integration into bone, (c) bone in outer ring and (d) bone in inner ring; score values ranged from 0 for physiological/original to 4 for clearly altered (table 1).

canal, thin, narrow-meshed bone trabeculae and occasionally only small bone particles could be observed around the LAE442 scaffolds. The structure of the cancellous bone around the La2 scaffolds was very inhomogeneous. In all week groups, often only very small bone fragments and in some cases a mixture of mostly thin and thick trabeculae occurred (figure 5(a)). In some cases of the 6-and 36 - weeks group, no bone was found in the vicinity of the La2 scaffolds. An increased occurrence of thin, narrow-meshed bone trabeculae was observed after 12 and 24 weeks (figure 5(b)). The TCP control group showed mainly a widely cross-linked, spongy bone and occasionally a mixture of thick and thin trabeculae in all time groups (figure 5(a)).

For the parameter 'integration of scaffold into bone', LAE442 showed an average of one direct contact per cross-section at all observation times, with 
a slight increase after 36 weeks. Although several bone trabeculae and in some cases large bone bridges occurred around most of the LAE442 scaffolds, these did not have direct contact to the scaffold but were separated by narrow gaps. However, isolated LAE442 scaffold areas also showed larger distances to the surrounding cancellous bone (figure 5(b)). The La2 scaffolds also showed on average one direct contact per cross-section after 6 and 12 weeks. Compared to LAE442, the distances between the surrounding cancellous bone and the La2 scaffolds were considerably larger. In the La2 week group 24 and 36 , increased contact between a few bone trabeculae and the degraded scaffold residues could be detected (figure 5(b)). The TCP implants showed close contact to the cancellous bone through several bone trabeculae punctuated with isolated gaps at all observation times (figure 5(b)).

For the parameter 'bone in the scaffold', about $2 \%-5 \%$ bone was observed in the LAE442 scaffolds after 6 weeks in 5/10 scaffolds in the outer ring and about $1 \%$ bone in $3 / 10$ scaffolds in the inner ring (figures 5(c) and (d)). In the remaining LAE442 scaffolds, no bone could be found after 6 weeks. At the subsequent implantation points, bone ingrowth in the pores became increasingly inhomogeneous, with the majority showing no bone or isolated small bone fragments in the outer area. However, in a few samples up to $10 \%$ bone within the pores of the LAE442 scaffolds could be observed. In comparison, no bone within the pores could be detected after 6 and 12 weeks in the La2 scaffolds. After 24 and 36 weeks, about $2 \%-5 \%$ bone in the outer area between the degraded scaffold residues could be observed. In the inner area, small bone trabeculae occurred only in single cases after 24 weeks of implantation. After 36 weeks, no bone was visible in the centre (figures 5(c) and (d)). The TCP implants showed the best values within the pores after 6 and 12 weeks, with an average of about $6 \%-10 \%$ bone in the outer ring and $2 \%-5 \%$ in the inner ring. After 24 and 36 weeks, TCP had over $10 \%$ bone in the outer ring and about $6 \%-10 \%$ in the inner ring (figures 5 (c) and (d)). Within the TCP implants, significantly more bone was found at all observation times than in the magnesium scaffolds $(p<0.001)$. LAE442 showed significantly more bone in the outer ring after 6 and 12 weeks $(p<0.001)$ in comparison to La2. At the original implantation site of La2, significantly more bone was observed after 24 and 36 weeks $(p<0.001)$ as compared to LAE442.

\subsubsection{Quantitative $\mu$ CT80 evaluation}

Due to the almost complete degradation of the La2 scaffolds after 24 and 36 weeks, the quantitative evaluations for these scaffolds could only be performed for the observation times 6 and 12 weeks.

Continuous and slow degradation of the scaffolds was observed in the LAE442 group, which was accompanied by a volume loss of $7.46 \%\left(2.7 \mathrm{~mm}^{3}\right)$ by week 36 . In comparison, a volume loss of $62.72 \%$ $\left(22 \mathrm{~mm}^{3}\right)$ with inhomogeneous degradation behaviour could already be observed in the La2 scaffolds after 12 weeks. The LAE442 scaffolds showed significantly more volume $(p=0.001)$ as compared to La2 at week 6 and 12. In terms of density, the LAE442 scaffolds showed a slight increase at all observation times as compared to their original density. A similar increase in density was observed in the La2 scaffolds after 6 and 12 weeks (figures 6(a) and (b)).

Analysis of the ingrown bone of LAE442 after 6 weeks revealed an average of $0.55 \mathrm{~mm}^{3}$ bonelike fractions in the pores of the scaffolds. After 12 and 24 weeks, the proportion of bone in the pores decreased, and at 36 weeks an average of $0.36 \mathrm{~mm}^{3}$ bone-like fractions within the pores could be observed (figure 6(c)). In the La2 scaffold, bonelike fractions averaging $0.05 \mathrm{~mm}^{3}$ after 6 weeks and small bone fragments averaging $0.19 \mathrm{~mm}^{3}$ after 12 weeks were observed in the outermost region of the already severely degraded scaffold sections (figure 6(c)). In the TCP control group, many small bone trabeculae between the implant residues (average $24.29 \mathrm{~mm}^{3}$ bone) could be detected after 6 weeks. At all subsequent observation times, fewer but thicker bone trabeculae (average $18.64 \mathrm{~mm}^{3}$ bone) occurred, which enclosed the remaining implant parts.

\subsection{Histological examination}

In the evaluation of the central cross-section, the La2 scaffolds showed rapid degradation with significantly less scaffold material $(p<0.001)$ after 24 and 36 weeks as compared to LAE442 (figures $7(\mathrm{a})-(\mathrm{h})$ ). In contrast, the LAE442 scaffolds remained relatively constant with respect to the amount of material and only showed an increasing amount of 'cracked' degradation layer until week 36 .

Until week 12, LAE442 showed more bone within the scaffolds in the central cross-section as compared to La2. After 24 weeks, more bone in the form of thin bone trabeculae between the La2 residues was observed as compared to LAE442. These bone trabeculae decreased again after 36 weeks in the area of the original scaffold localization of La2 (figure 8(b)).

LAE442 in particular showed an increasing amount of poorly mineralized, osteoid-like bone matrix within the scaffold pores of more than $25 \%$ by week 24 , with an increasing number of empty osteocyte lacunae over time. Between the remains of the La2 scaffolds, poorly mineralized bone matrix was also observed after 24 and 36 weeks (figure 8(c)).

After 6 and 12 weeks, granulation tissue was rarely present in La2 and only in the peripheral area of these scaffolds. The La2 scaffolds showed a strong accumulation of gas within the scaffolds. From week 24 onwards, a small accumulation of gas and more granulation tissue between the scaffold residues of $\mathrm{La} 2$ were observed. No gas could be detected in La2 after 

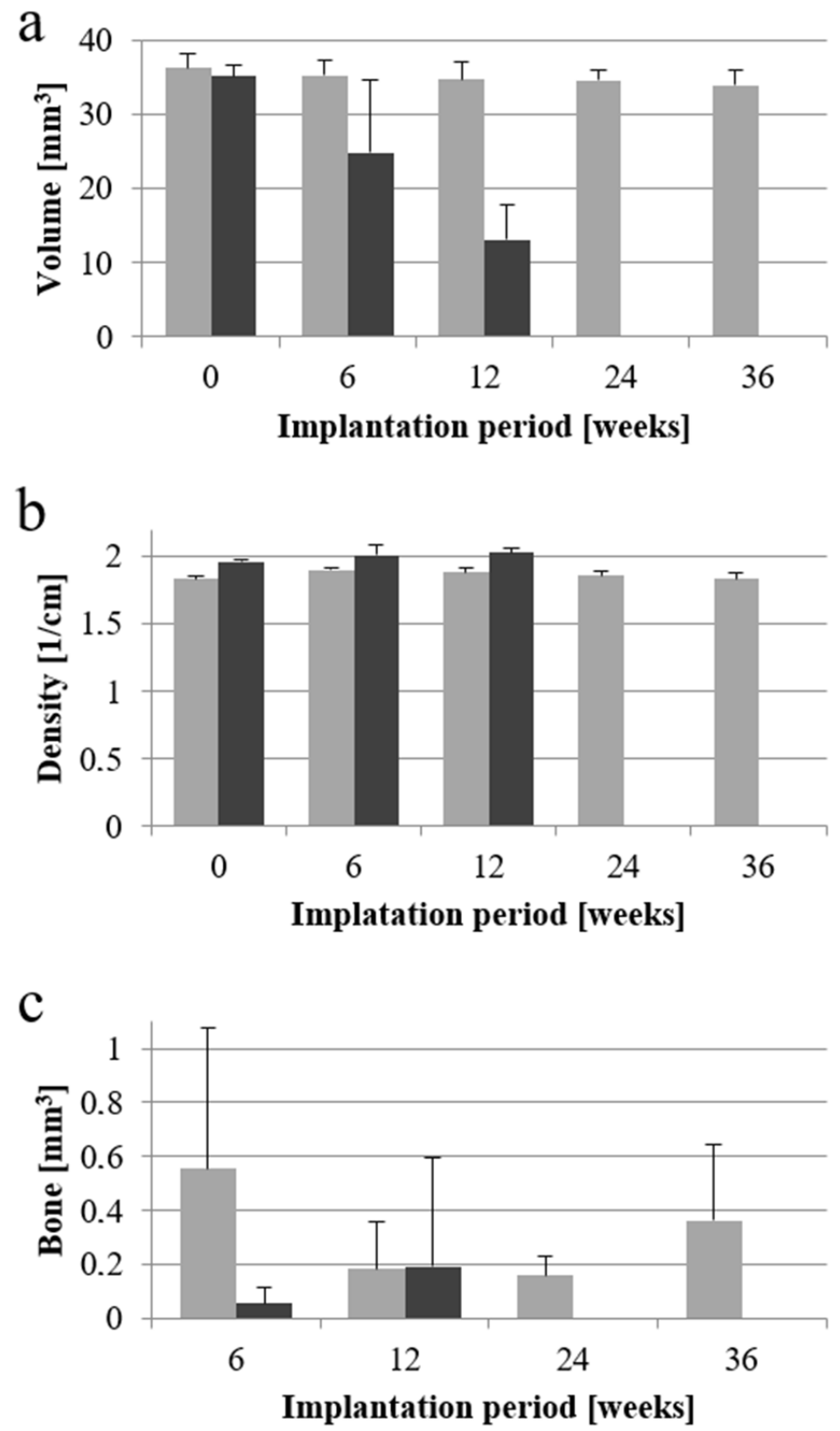

\section{LAE442 - La2}

Figure 6. Quantitative $\mu$ CT80 evaluation of magnesium scaffolds LAE442 and La2: (a) scaffold volume, (b) scaffold density, and (c) bone within the scaffold pores (La2 scaffolds after 24 and 36 weeks were non-evaluable).

36 weeks (figures $8(\mathrm{a})$ and $(\mathrm{d})$ ). Within the LAE442 scaffolds, the low to moderate gas accumulation as well as the amount of granulation tissue $(<10 \%)$, which was also found in the scaffold centre, decreased slightly over the observation period (figures 8(a) and $(\mathrm{d}))$. After 24 and 36 weeks, LAE442 showed significantly less granulation tissue $(p<0.001)$ and after 36 weeks significantly more gas $(p<0.001)$ compared to the La2 scaffolds. In the TCP control group, no gas in and around the scaffolds and more than $25 \%$ granulation tissue within the implants could be observed at all time groups (figures $8(\mathrm{a})$ and (d)).
After 6 and 12 weeks, half of the La2 cross-sections were surrounded by up to $50 \%$ by gas and in the other half over $50 \%$ of the implant surface was surrounded by gas. In two cases, after 24 weeks up to $25 \%$ of the remaining scaffold material was still covered by gas and after 36 weeks no gas was found around the La2 residues. In the LAE442 scaffolds, the gas accumulation in the direct vicinity of the scaffold remained relatively constant at all observation times between $25 \%$ and $50 \%$ (score 2 ) and over $50 \%$ (score 3 ) with a maximum after 24 weeks.

Direct bone-to-scaffold contact was observed only in single LAE442 cross-sections at several sites. 


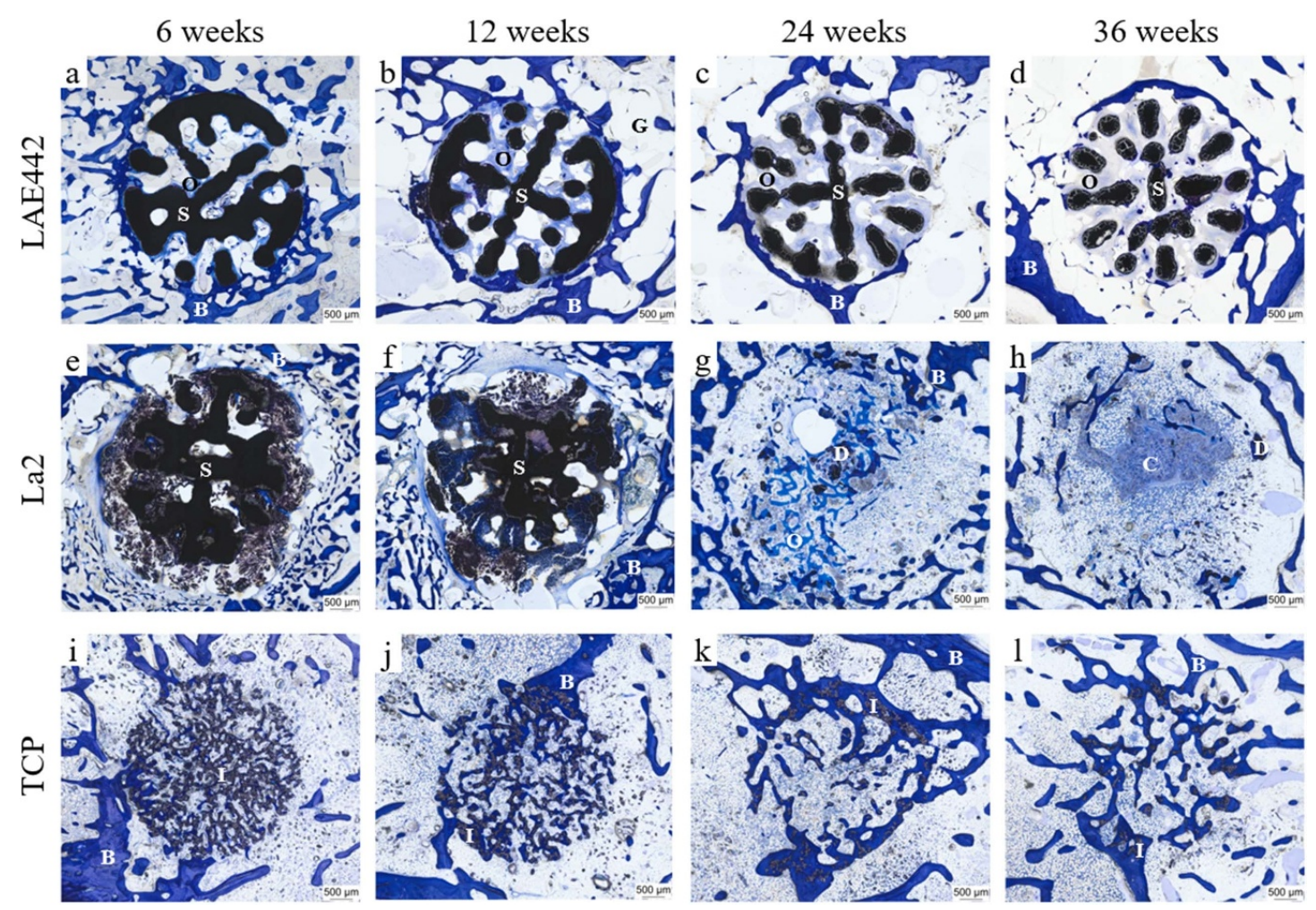

Figure 7. Histological cross-sections of LAE442, La2 and TCP, toluidine blue: (a)-(d) LAE442, (e)-(h) La2 and (i)-(1) TCP; $\mathrm{B}=$ bone, $\mathrm{G}=$ gas, $\mathrm{O}=$ osteoid-like non-mineralized bone matrix, $\mathrm{S}=$ scaffold material (magnesium), $\mathrm{I}=$ implant material (TCP), $\mathrm{FC}=$ fibrous capsule, $\mathrm{D}=$ debris, $\mathrm{C}=$ cell cluster.
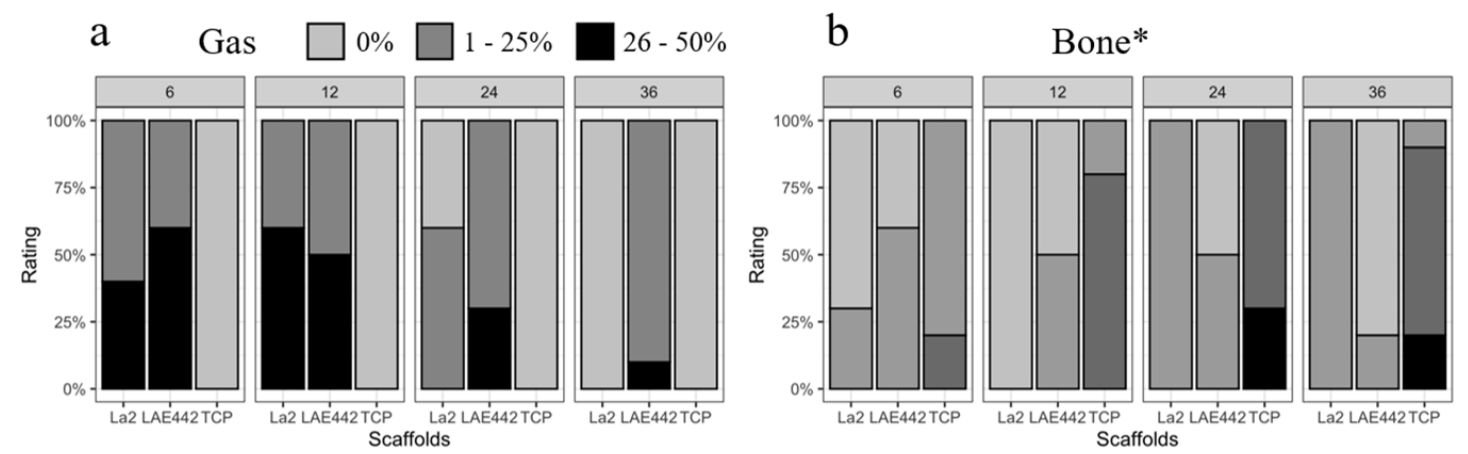

c Non-mineralized bone matrix*
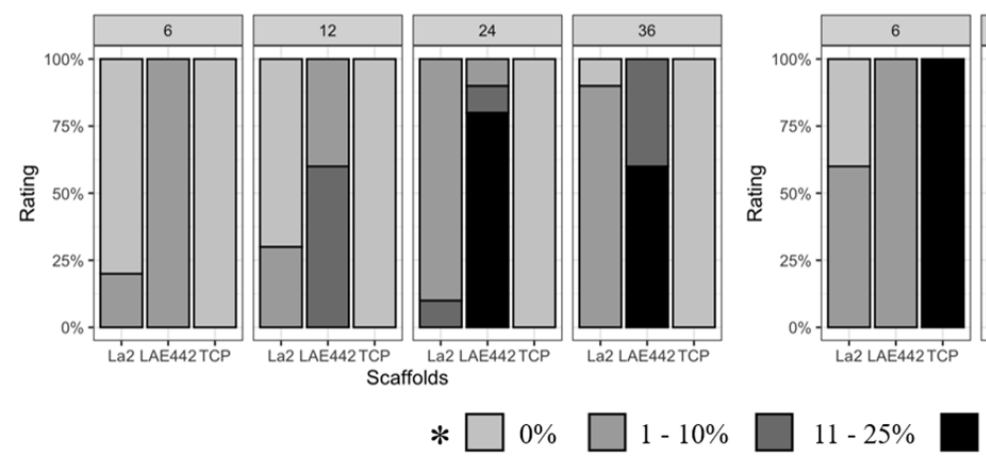

Granulation tissue*

Figure 8. Results of the histological evaluation ( $25 \times$ magnification) within the scaffold ( $4 \mathrm{~mm}$ diameter circle): (a) gas, (b) bone, (c) non-mineralized bone matrix, and (d) granulation tissue. 

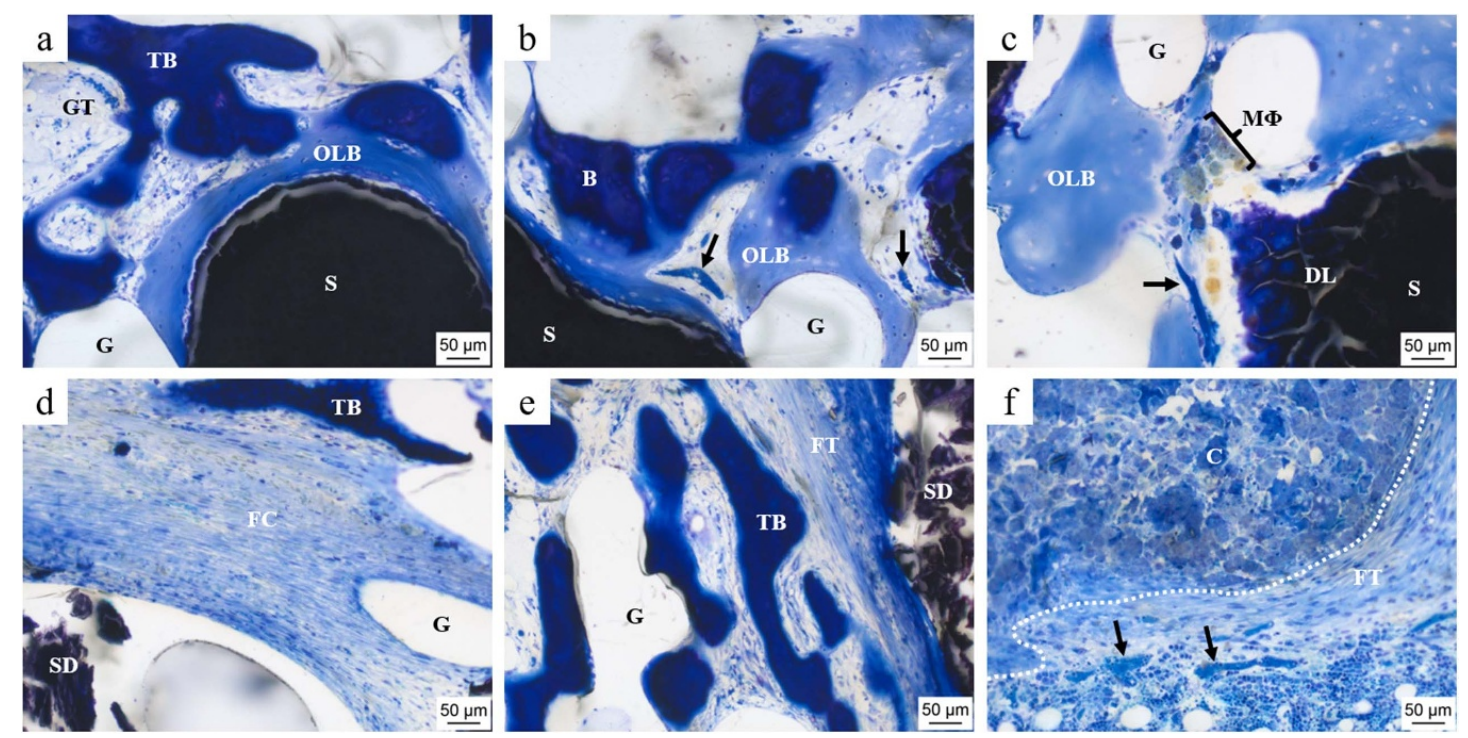

Figure 9. Histological images, toluidine blue: (a), (b) LAE442 after 6 weeks, (c) LAE442 after 24 weeks, (d), (e) La2 after 12 weeks and (f) La2 after 36 weeks; $\mathrm{S}=$ scaffold, $\mathrm{SD}=$ scaffold debris, $\mathrm{DL}=$ degradation layer with cracks, $\mathrm{B}=\mathrm{bone}, \mathrm{TB}=$ trabecular bone, $\mathrm{G}=$ gas, $\mathrm{GT}=$ granulation tissue, $\mathrm{OLB}=$ osteoid-like bone matrix, $\mathrm{FC}=$ fibrous capsule, $\mathrm{FT}=$ fibrous tissue, $\mathrm{C}=$ cell cluster (macrophages and FBCs; marked with white dotted line), $\mathrm{M} \Phi=$ macrophages (marked with black brace), black arrows $=$ blood vessels.

In the majority of the LAE442 scaffolds, a connection between the scaffold material and the surrounding bone could be demonstrated via a poorly mineralized bone matrix (figure 9(a)). The proportion of the poorly mineralized bone substance surrounding the scaffold surface increased significantly over time. In La2, direct contact between the scaffold and the surrounding bone by isolated bone trabeculae was observed in individual cases after 6 and 12 weeks. Otherwise, strong resorption of the surrounding cancellous bone was visible. After 24 and 36 weeks, the remaining La2 scaffold residues were directly enclosed by bone.

A fibrous capsule formation around the scaffolds was observed in La2 in varying degrees after 6 and 12 weeks (figures $9(\mathrm{~d})$ and $10(\mathrm{a})$ ). In addition, a strong network of thin trabeculae formed behind and between the fibrous tissue at some distance from the scaffolds (figure 9(e)). In comparison, only a moderate number of fibrocytes in the granulation tissue could be detected in LAE442 (figure 10(a)).

In the LAE442 scaffolds, a moderate number of blood vessels was found after 6 and 12 weeks (figures 9(b) and 10(b)), with slightly fewer blood vessels in the centre of the scaffolds as compared to the peripheral area. Subsequently, after 24 and 36 weeks, the number of blood vessels decreased and only a few were present within the scaffolds (figures 9 (c) and 10(b)). In the La2 scaffolds, no or only isolated blood vessels could be observed in the marginal area of the scaffolds after 6 and 12 weeks of implantation. After 24 and 36 weeks, few blood vessels appeared between the La2 residues. TCP showed a moderate number of blood vessels within the implant residues in all time groups (figure 10(b)).

LAE442 demonstrated an overall increasing but moderate number of macrophages and a few FBCs in and around the scaffolds over the entire observation period. In La2, no macrophages and FBCs were observed in the central or middle area of the scaffolds after 6 and 12 weeks. However, an increasing number of macrophages and FBCs occurred in the immediate vicinity of the La2 scaffolds (figures 10(c) and (d)). From week 24 onwards, a strong accumulation of macrophages and FBCs was observed in the centre of the original scaffold localization (figure $9(\mathrm{f})$ ). The TCP control group showed no foreign body reaction (macrophages and FBCs) and had sporadic neutrophil granulocytes. Overall, no signs of an inflammatory reaction could be observed in any material group.

\subsection{SEM/EDX}

The SEM images of LAE442 revealed a darker degradation layer with increasing extent over time with an accumulation of calcium and phosphorus [2]. In some places the degradation layer had a doublelayered structure with a bright outer and a darker underlying part (figures 11(a) and (b)). Comparing these two layers, the darker layer had a higher magnesium content and the brighter layer had a higher calcium and phosphorus content (table 3). On the scaffold surface of LAE442, fluorine, a component of the $\mathrm{MgF}_{2}$ coating, could be detected to varying extents depending on localization and implantation period. A general decrease could be observed to 0.8 wt.\% fluorine after 36 weeks. Furthermore, 


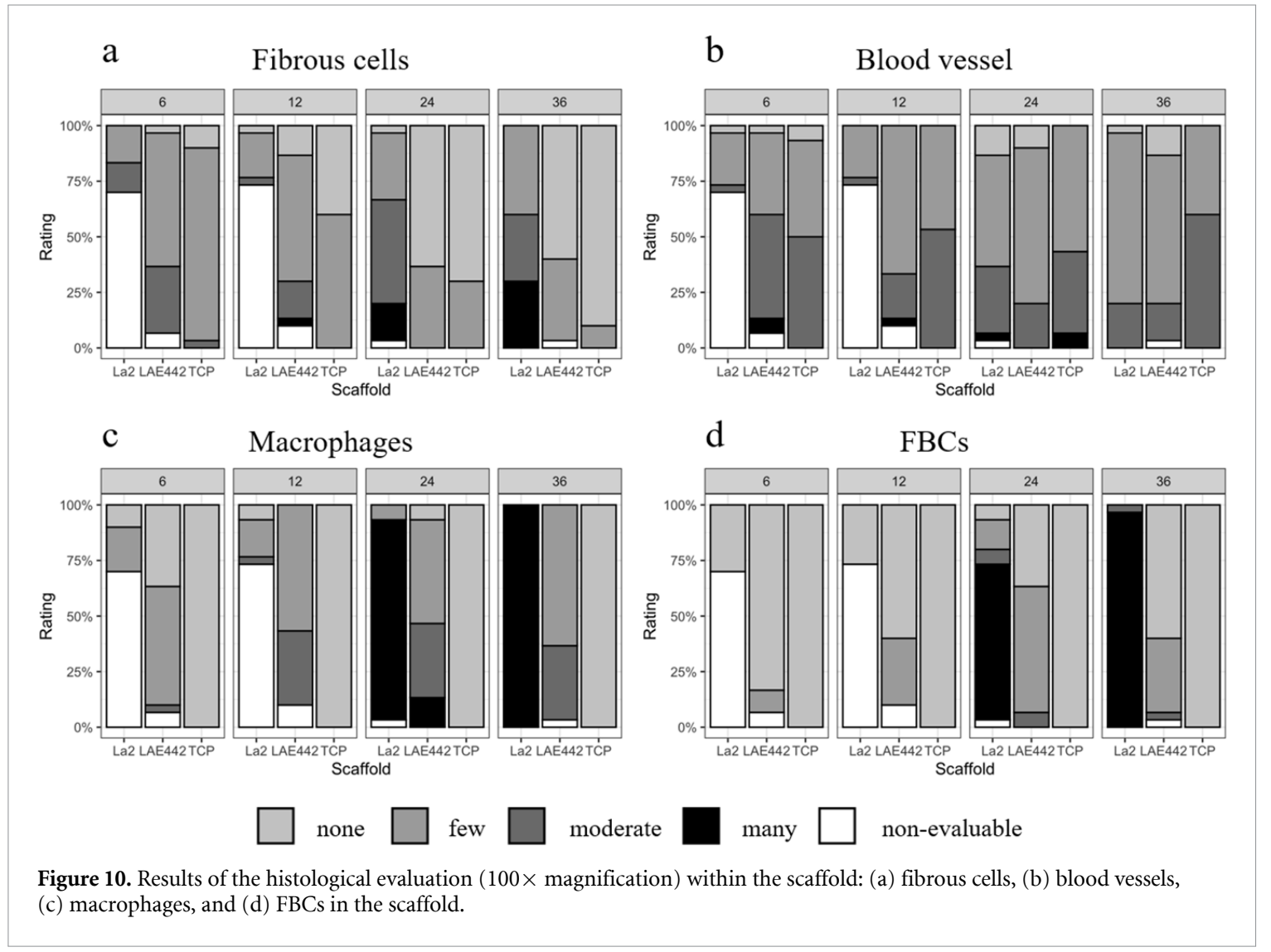

the contact between the scaffold material of LAE442 and the surrounding bone was often observed via an intermediate matrix with calcium and phosphorus as the main components (table 3 ). This scaffoldmatrix-bone connection was increasingly observed in the implantation periods of 24 and 36 weeks (figures 11(c) and (d)).

In the La2 scaffolds, the scaffold material and the strongly increasing degradation layer could be identified in the SEM images only until 12 weeks after implantation. Thereby fluorine was detected on the scaffold surface with 22.8 wt.\% after 6 weeks and 1.6 wt.\% after 12 weeks. From week 24 on, small degraded scaffold particles, as well as bone and clusters of small, roundish structures (identified on the histological sections as cell clusters of macrophages and FBCs) could be observed in the original implantation area using SEM images (figures 11(e) and (f)). Within the described cell clusters, the EDX analysis of a La2 cross-section after 36 weeks showed a strong accumulation of lanthanum of up to $67.3 \mathrm{wt} . \%$ (table 3).

\section{Discussion}

The objective of the present study was to compare the biocompatibility, the ingrowth of the surrounding tissue and the degradation behaviour of the magnesium scaffolds La2 and LAE442 with defined interconnecting pores in vivo. Commercially available porous $\beta$-TCP implants of the same dimensions served as a control group. So far, the alloy LAE442 has been investigated in many in vivo studies only as solid implants, such as intramedullary pins or screws [27-29]. The binary alloy Mg-La2 exhibited good properties in vitro, allowing the investigation of this alloy in vivo [32]. Previous investigations focused mainly on magnesium scaffolds with a random and irregular pore distribution [7, 33, 40, 44, 47]. In order to increase the reproducibility and stability of the implants, magnesium scaffolds with defined pore structures were developed for this study. In vitro investigations by Julmi et al showed sufficient stability of the open-pored magnesium scaffolds LAE442 and La2 to withstand the forces occurring in the rabbit bone [41]. In the study by Kleer et al, these two alloys LAE442 and Mg-La2 were examined in vivo in the form of open-pored magnesium scaffolds in the rabbit model by means of clinical, radiological and $\mu \mathrm{CT}$ analyses, and LAE442 in particular showed a slow and homogenous degradation [43]. In the present in vivo study, each bone-scaffold compound was examined in more detail after the respective observation time of $6,12,24$ or 36 weeks using high-resolution $\mu \mathrm{CT} 80$ scans. In addition, histological examinations were conducted to assess biocompatibility and EDX analyses were performed on cross-sections to evaluate the distribution of elements in areas of special interest.

Using ex vivo $\mu \mathrm{CT} 80$ scans, the degradation of the scaffolds could be assessed in higher resolution compared to the in vivo $\mu \mathrm{CT}$ images of the study by Kleer et al [43]. The ex vivo scans revealed the degradation 

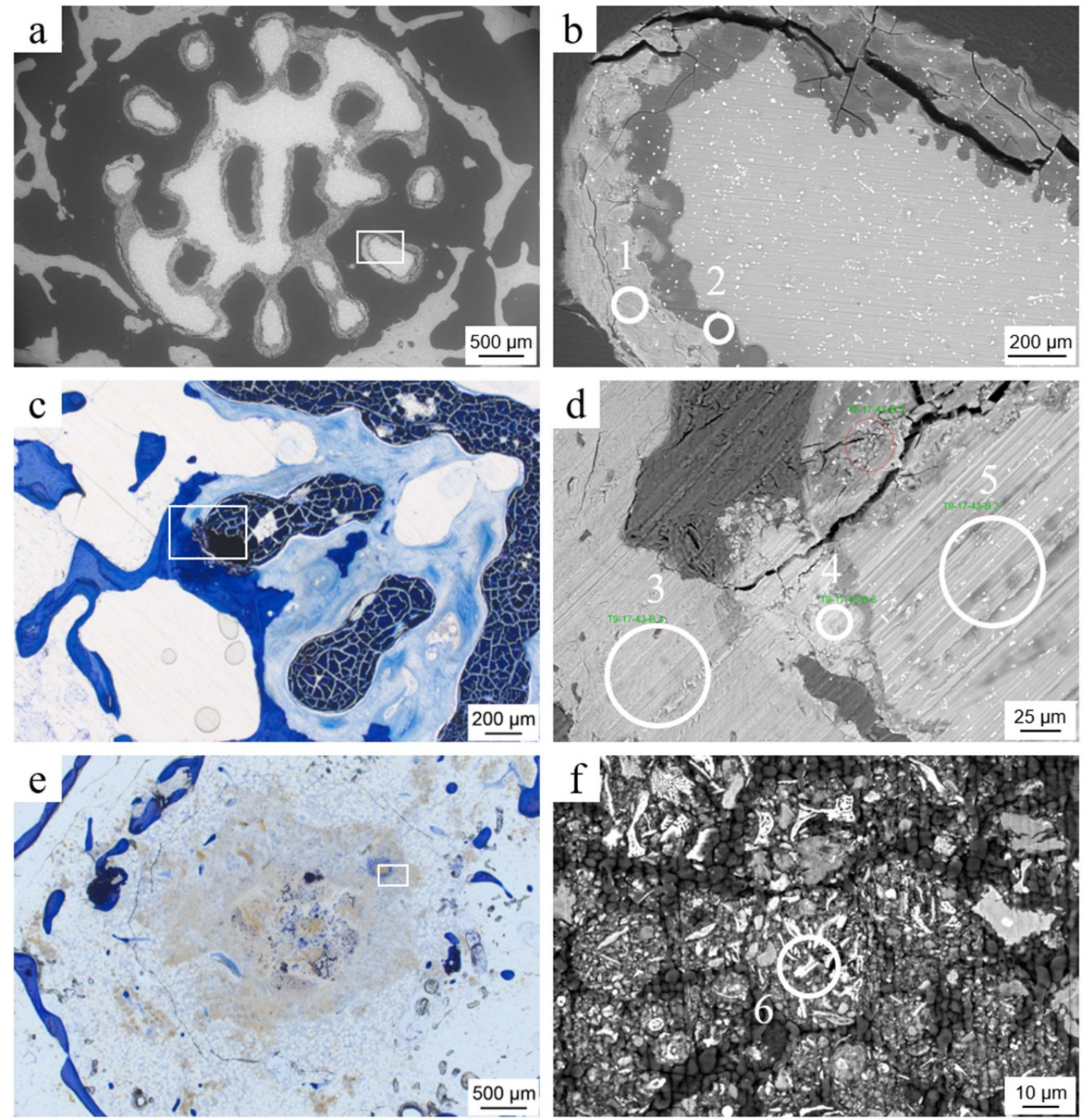

Figure 11. SEM and histological images: (a), (b) SEM images of LAE442 after 24 weeks, degradation layer, double-layered structure with bright outer (1) and darker underlying (2) part; (c) LAE442 after 36 weeks (d) magnification: intermediate matrix (4) as contact between bone (3) and scaffold (5); (e) La2 after 36 weeks: large cell clusters (macrophages and FBCs), (f) magnification: roundish structures with bright particles; positions (1-6) marked in (b), (b) and (f) indicate the locations of the EDX analyses presented in table 3.

layer and bright deposits on the scaffolds. These bright deposits were probably the accumulation of calcium and phosphorus, as verified in the EDX analyses of the LAE442 scaffolds. In the $\mu \mathrm{CT} 80$ images of LAE442 fine gaps were often visible between the surrounding bone trabeculae and the scaffold, which could not be detected in the in vivo investigations by Kleer et al [43]. Using the histological sections these apparent gaps could be determined as an osteoid-like bone matrix. As described in other studies, this was a poorly mineralized bone matrix and therefore did not appear bone dense in the $\mu \mathrm{CT} 80$ images $[33,48]$. As a result, less frequent direct bone-to-scaffold contacts were evaluated for LAE442 in the present study compared to the study by Kleer et al [43]. As in the in vivo study [43], one direct bone-to-scaffold contact per cross-section was observed on average for the La2 scaffolds. In most cases, one thick bone trabeculae grew from the periphery directly to the La2 scaffolds with otherwise large gaps to the surrounding cancellous bone. This observation of inhomogeneous integration also occurred in the study by Lalk et al on porous AX30 magnesium scaffolds with CaP-coating. Many of the scaffolds had completely lost contact with the surrounding cancellous bone and exhibited wide gaps [33].

In the $\mu \mathrm{CT} 80$ images, isolated bone dense islands within the pores of the LAE442 scaffolds were observed, most of which had no direct contact to the scaffold material. This phenomenon of isolated bone islands was also observed by Lalk et al within the pores of the $\mathrm{MgF}_{2}$-coated $\mathrm{AX} 30$ scaffolds. These bony 
Table 3. EDX data for LAE442 and La2 scaffolds: LAE442 after 24 weeks, degradation layer, dark part (position 1) and bright part (position 2); LAE442 after 36 weeks, bone-to-scaffold contact, bone (position 3), intermediate matrix (position 4), scaffold (position 5); La2 after 36 weeks, cell clusters, within a cell (position 6); positions 1-6 are marked in figure 10.

\begin{tabular}{|c|c|c|c|c|c|c|}
\hline \multirow[b]{3}{*}{ Element } & \multicolumn{6}{|c|}{ Concentration in wt.\% } \\
\hline & \multicolumn{2}{|c|}{ LAE442 24 weeks } & \multicolumn{3}{|c|}{ LAE442 36 weeks } & \multirow{2}{*}{$\frac{\text { La2 } 36 \text { weeks }}{6}$} \\
\hline & 1 & 2 & 3 & 4 & 5 & \\
\hline $\mathrm{Mg}$ & 72.7 & 32.0 & 7.8 & 23.1 & 89.2 & 1.0 \\
\hline $\mathrm{Al}$ & 12.9 & 4.5 & 0.7 & 2.6 & 3.4 & 1.6 \\
\hline $\mathrm{La}$ & 0.2 & - & - & - & 0.6 & 67.3 \\
\hline $\mathrm{Ce}$ & 1.3 & 2.0 & - & - & 1.1 & - \\
\hline $\mathrm{Si}$ & 0.3 & 0.2 & 0.8 & 0.2 & 0.5 & - \\
\hline $\mathrm{P}$ & 3.8 & 17.7 & 26.3 & 17.6 & 1.6 & 18.7 \\
\hline $\mathrm{Ca}$ & 6.8 & 41.4 & 62.4 & 53.9 & 3.0 & 9.2 \\
\hline $\mathrm{Na}$ & 1.1 & 2.2 & 1.6 & 2.5 & - & - \\
\hline S & 0.1 & - & 0.4 & - & 0.6 & 1.1 \\
\hline $\mathrm{K}$ & - & - & - & - & - & 0.2 \\
\hline $\mathrm{Fe}$ & - & - & - & - & - & 1.0 \\
\hline $\mathrm{Mn}$ & 0.4 & - & - & - & - & - \\
\hline $\mathrm{Cl}$ & 0.4 & - & - & 0.2 & - & - \\
\hline
\end{tabular}

islands were surrounded by poorly mineralized bone matrix which did not appear bone dense in $\mu \mathrm{CT} 80$ [33]. The presence of poorly mineralized bone matrix could be confirmed in the present study using the histological sections.

In assessing the structure of the surrounding bone, TCP mainly showed a physiological widemeshed bone structure, as also observed in the control group 'empty drill holes' after 12 and 24 weeks in the study by Lalk et al [33]. This wide-meshed bone could only be observed after 24 weeks around the AX30 $\mathrm{MgF}_{2}$-coated scaffolds and only in half of the CaP-coated scaffolds [33]. The remaining CaP-coated scaffolds showed only a narrow-meshed bone structure at 24 weeks [33], which could also be observed within a certain range around the La2 scaffolds after 6 and 12 weeks. In comparison, the LAE442 scaffolds in the present study exhibited a better bone structure in the immediate vicinity with mostly a mixture of thin and thick trabeculae and only a few large gaps.

$\mu \mathrm{CT} 80$ images of the bone-scaffold compounds showed, accumulation of gas within and directly around the magnesium scaffolds, but not in the TCP control group. During the degradation of magnesium, hydrogen is formed, which accumulates if it cannot be sufficiently absorbed or removed by the surrounding tissue and blood vessels $[13,20]$. However, in the in vivo study by Kleer et al and in other studies, the accumulation of gas inside the bone had no clinical effects such as lameness or signs of pain on the animals [43, 49, 50].

The histological evaluation of implants is one of the most important methods for assessing their biocompatibility [51]. In the present study, as well as in many other studies [44, 52, 53], parameters such as newly formed bone and osteoid, the amount of blood vessels and fibrous tissue, as well as inflammatory reactions and foreign body reactions (particularly evident in the presence of macrophages and FBCs) were examined.

In addition, the evaluation of the scaffold material in the present histological examination revealed 'cracks' in the degradation layer of the LAE442 scaffolds to an increasing extent over the implantation periods. Ullmann et al microscopically observed cracks on the implant surface of LAE442 pins after an implantation period of 6 months [30]. In the study by Rössig et al, cracks in the degradation layer of the LAE442 implants in the sheep model were visible in the histological sections after 24 weeks [54]. As early as 1900, while investigating Mg implants for vascular surgery, Payr reported a rough surface on the implants after $24 \mathrm{~h}$ and many furrows and cracks in the implants after three to four days up to the complete dissolution of the metal [55]. However, the 'cracks' in the present study could also be artefacts formed in the more unstable degradation layer during the preparation of the histological samples. In the study by Kraus et al, cracks in the oxide layer of Febased implants were attributed to dehydration during sample preparation [56]. Subsequent investigations are necessary to clarify this phenomenon and the possible impact on the stability of the scaffolds.

More bone within the scaffolds was found in LAE442 compared to La2 by week 12 . Small, thin bone trabeculae were detected after 24 weeks in the original scaffold localization of La2, after only residuals of the scaffolds and hardly any gas remained. This phenomenon of regeneration of the surrounding bone was also observed in the study by Kraus et al after almost complete degradation of ZX50 implants and thus decreasing gas formation [57].

In the present study, an increasing amount of poorly mineralized, osteoid-like bone matrix was found over the implantation periods, especially within the pores of the LAE442 scaffolds. A few pores 
of LAE442 were completely filled with this poorly mineralized bone matrix. The study by Lalk et al also revealed unusually wide osteoid formations of up to $220 \mu \mathrm{m}$ in the area of porous AX30 magnesium scaffolds [33]. To a lesser extent, this was also observed in the original scaffold localization of the La2 scaffolds after 24 and 36 weeks in the form of thin, poorly mineralized trabeculae. Significantly more osteoid compared to the control group was also found in the study by Witte et al in the peri-implant area around the porous AZ91D scaffolds [40]. Besides other factors, the fluoride in the coating could lead to increased osteoid formation by stimulating osteoblastic activity and delay the mineralisation of new bone. This mechanism was described by Mousny et al after oral application of fluoride in a mouse model [48]. Furthermore, there is a controversial discussion in the literature about whether aluminium, which is a component of the LAE442 alloy, has a negative influence on mineralisation and delays this process [58-60]. The exact mechanisms of incomplete mineralization could not be conclusively clarified in this study. However, it appears to be a multifactorial process, since the osteoid-like bone matrix was present in both magnesium alloys to a different extent.

Within the pores of LAE442 scaffolds, a moderate number of blood vessels could be detected histologically in the early time groups ( 6 and 12 weeks), as well as within the TCP implants at all implantation times. In contrast, no blood vessels were found within the La2 scaffolds after 6 and 12 weeks and subsequently (24 and 36 weeks), as with the LAE442 scaffolds, only a few blood vessels were observed. Vascularisation in the area of the bone graft substitutes is of critical importance for osseointegration [9]. In the study by Cheng et al, the $400 \mathrm{PMg}$ scaffolds with the larger pores in a rabbit model showed higher vascularisation compared to the smaller pore size, which could be the reason for the increased bone formation [47]. Overall, the TCP control group showed the best vascularization and osseointegration in the present study, as well as the largest amount of ingrown bone compared to both magnesium scaffolds. However, the mechanical properties such as the stability of $\beta$-TCP are not sufficient for the application in weight-bearing bone defects [12].

The presence of macrophages and FBCs, as well as the formation of granulation tissue, is considered to be a normal response to implanted degradable biomaterials [4]. In the long-term study by Angrisani et al, investigating intramedullary LAE442 pins in a rabbit model, the presence of macrophages and giant cells for removal of corrosion products of the LAE442 pins was assessed as good cellular compatibility [26]. Therefore, the mild to moderate presence of macrophages and FBCs in the LAE442 scaffolds is considered as a normal reaction to the biomaterial during the degradation process and indicates good biocompatibility. In comparison, no or hardly any granulation tissue and thus no cells were detected due to gas within the pores of the La2 scaffolds after 6 and 12 weeks. Subsequently, a very strong accumulation of macrophages and FBCs was observed in the original scaffold localization of the La2 scaffolds after 24 and 36 weeks, partially surrounded by fibrous tissue. Only a moderate number of fibrocytes occurred in the granulation tissue of the LAE442 scaffolds, but there was no capsule formation. In comparison, the $\mathrm{La} 2$ scaffolds in the present study showed an overly rapid degradation, associated with a distinct fibrous capsule formation after 6 and 12 weeks. This formation of a fibrous capsule around a biomaterial is induced by the body to protect the surrounding host tissue [4]. Furthermore, in the present study, the increased accumulation of gas around the La2 scaffolds may also have influenced the extent of capsule formation. According to the study by Nuss et al, the combination of a thick fibrous capsule and a high number of macrophages and FBCs indicates insufficient biocompatibility [4], as can be assumed for the La2 scaffolds.

In addition, the EDX analysis in the area of these cell clusters (macrophages and FBCs), which were observed in La2 scaffolds after 36 weeks, showed an increased concentration of lanthanum of up to 67.3 wt.\%. Free lanthanides have an affinity to accumulate in the bone due to their similar physicochemical properties to calcium [61]. A progressive loss of membrane integrity in macrophages was observed in the in vitro study by Southwick et al after exposure to lanthanum [62]. Feyerabend et al reported a reduction in cell viability of the macrophage cell line RAW 264.7 after a lanthanum exposure time of $24 \mathrm{~h}$ [63]. Thus, the large clusters of macrophages and FBCs in the original scaffold localization of La2 could probably be associated with apoptosis of these cells due to the lanthanum accumulation.

Furthermore, the $\mathrm{MgF}_{2}$ coating was investigated by means of EDX analysis. In the present study, about $2 / 3$ of the original fluoride disappeared from the scaffold surface after 6 weeks and hardly any fluoride could be detected after 12 weeks. In contrast, Witte et al described less than 1 wt.\% fluoride on the implant surface after only 4 weeks and thus a complete disappearance of the initial $\mathrm{MgF}_{2}$ coating (thickness 150-200 $\mu \mathrm{m}$ ) on the LAE442 implants [29]. Despite the same alloy and coating manufacturing process, fluoride lasted longer in the present study than by Witte et al, although the initial coating was much thinner. Subsequent studies with more frequent investigation time points would be necessary to accurately evaluate the reduction of corrosion provided by the $\mathrm{MgF}_{2}$ coating.

The EDX analysis of the LAE442 scaffolds showed both an accumulation of calcium and phosphorus in the degradation layer and a deposition of both elements on the scaffold surface, as already described earlier [2]. This fact could explain the increasing density of the LAE442 scaffolds observed in 
$\mu \mathrm{CT} 80$ over time. In many other in vivo studies, this accumulation of a mineralized phase of calcium and phosphorus in the degradation layer of magnesium implants has been observed [30, 35, 64]. In the present study, these deposits of calcium and phosphorus on the LAE442 scaffolds showed direct contact to the surrounding bone, also described by Witte et al for porous AZ91D scaffolds in a rabbit model [13].

\section{Conclusion}

In summary, the present study showed an inhomogeneous and fast degradation for La2. In addition, the La2 scaffolds exhibited an inadequate osseointegration with fibrous capsule formation in the early implantation periods and a foreign body reaction at later implantation periods. LAE442, on the other hand, showed direct bone-to scaffold contact, a homogeneous degradation behaviour and almost maintained its original shape up to 36 weeks. Within the pores of the LAE442 scaffolds vascularization, moderate cellular response, as well as granulation tissue and bone were observed at all implantation periods. Furthermore, osteoid-like bone matrix was detected on the scaffold surface and within the pores of LAE442. Based on the results of this study, porous LAE442 showed promise as degradable scaffolds for bone defect repair in terms of degradation behaviour and biocompatibility. However, further studies are needed to show it would have the necessary mechanical properties required over time for weightbearing bone defects. Moreover, additional coatings (for example $\mathrm{CaP}$ ) could further delay the degradation rate and gas production and might have a positive effect on the mineralisation of the osteoid-like bone matrix.

\section{Data availability statement}

The data that support the findings of this study are available upon reasonable request from the authors.

\section{Acknowledgments}

The authors gratefully acknowledge the financial support by the German Research Foundation (DFG) within the project 'Interfacial effects and integration behaviour of magnesium-based sponges as bioresorbable bone substitute material' (Funding Number 271761343). Furthermore, the authors thank Lisa Wurm and Beatrix Limmer for their excellent technical support, Yury Zablotski for his help with the statistical analysis and Brigitte von Rechenberg for her input regarding the histological evaluation.

\section{ORCID iD}

N Kleer-Reiter (1) https://orcid.org/0000-0002-68539040

\section{References}

[1] Liang H, Li X, Shimer A L, Balian G and Shen F H 2014 A novel strategy of spine defect repair with a degradable bioactive scaffold preloaded with adipose-derived stromal cells Spine J. 14 445-54

[2] Maier H J, Julmi S, Behrens S, Klose C, Gartzke A-K, Wriggers P, Waselau A-C and Meyer-Lindenberg A 2020 Magnesium alloys for open-pored bioresorbable implants JOM 72 1859-69

[3] de Long W G Jr, Einhorn T A, Koval K, McKee M, Smith W, Sanders R and Watson T 2007 Bone grafts and bone graft substitutes in orthopaedic trauma surgery. A critical analysis J. Bone Joint Surg. Am. 89 649-58

[4] Nuss K M and von Rechenberg B 2008 Biocompatibility issues with modern implants in bone-a review for clinical orthopedics Open Orthop. J. 2 66-78

[5] Karageorgiou V and Kaplan D 2005 Porosity of 3D biomaterial scaffolds and osteogenesis Biomaterials 26 5474-91

[6] Yazdimamaghani M, Razavi M, Vashaee D, Moharamzadeh K, Boccaccini A R and Tayebi L 2017 Porous magnesium-based scaffolds for tissue engineering Mater. Sci. Eng. C 71 1253-66

[7] Bobe K, Willbold E, Morgenthal I, Andersen O, Studnitzky T, Nellesen J, Tillmann W, Vogt C, Vano K and Witte F 2013 In vitro and in vivo evaluation of biodegradable, open-porous scaffolds made of sintered magnesium W4 short fibres Acta Biomater. 9 8611-23

[8] Klenke F M, Liu Y, Yuan H, Hunziker E B, Siebenrock K A and Hofstetter W 2008 Impact of pore size on the vascularization and osseointegration of ceramic bone substitutes in vivo J. Biomed. Mater. Res. A 85 777-86

[9] Mavrogenis A F, Dimitriou R, Parvizi J and Babis G C 2009 Biology of implant osseointegration J. Musculoskelet. Neuronal Interact. 9 61-71

[10] Bohner M, Baroud G, Bernstein A, Doebelin N, Galea L, Hesse B, Heuberger R, Meille S, Michel P and von Rechenberg B 2017 Characterization and distribution of mechanically competent mineralized tissue in micropores of $\beta$-tricalcium phosphate bone substitutes Mater. Today 20 106-15

[11] von Doernberg M C, von Rechenberg B, Bohner M, Grunenfelder S, van Lenthe G H, Muller R, Gasser B, Mathys R, Baroud G and Auer J 2006 In vivo behavior of calcium phosphate scaffolds with four different pore sizes Biomaterials 27 5186-98

[12] Dorozhkin S V 2010 Bioceramics of calcium orthophosphates Biomaterials 31 1465-85

[13] Witte F, Kaese V, Haferkamp H, Switzer E, Meyer-Lindenberg A, Wirth C J and Windhagen H 2005 In vivo corrosion of four magnesium alloys and the associated bone response Biomaterials 26 3557-63

[14] Ayvaz M, Bekmez S, Yucekul A, Mermerkaya M U and Tokgozoglu A M 2018 Titanium mesh cage as an alternative reconstruction method for epiphyseal-sparing tumour resections in children J. Pediatr. Orthop. B 27 350-5

[15] Segal U and Shani J 2010 Surgical management of large segmental femoral and radial bone defects in a dog: through use of a cylindrical titanium mesh cage and a cancellous bone graft Vet. Comp. Orthop. Traumatol. 23 66-70

[16] Nagels J, Stokdijk M and Rozing P M 2003 Stress shielding and bone resorption in shoulder arthroplasty J. Shoulder Elbow Surg. 12 35-39 
[17] Staiger M P, Pietak A M, Huadmai J and Dias G 2006 Magnesium and its alloys as orthopedic biomaterials: a review Biomaterials 27 1728-34

[18] Willbold E et al 2013 Biocompatibility of rapidly solidified magnesium alloy RS66 as a temporary biodegradable metal Acta Biomater. 9 8509-17

[19] Vormann J 2003 Magnesium: nutrition and metabolism Mol. Aspects Med. 24 27-37

[20] Song G and Atrens A 2003 Understanding magnesium corrosion-a framework for improved alloy performance Adv. Eng. Mater. 5 837-58

[21] Janning C, Willbold E, Vogt C, Nellesen J, Meyer-Lindenberg A, Windhagen $\mathrm{H}$, Thorey $\mathrm{F}$ and Witte $\mathrm{F}$ 2010 Magnesium hydroxide temporarily enhancing osteoblast activity and decreasing the osteoclast number in peri-implant bone remodelling Acta Biomater. 6 1861-8

[22] Witte F, Hort N, Vogt C, Cohen S, Kainer K U, Willumeit R and Feyerabend F 2008 Degradable biomaterials based on magnesium corrosion Curr. Opin. Solid State Mater. Sci. 12 63-72

[23] Willbold E et al 2015 Effect of the addition of low rare earth elements (lanthanum, neodymium, cerium) on the biodegradation and biocompatibility of magnesium Acta Biomater. 11 554-62

[24] Acar B, Kose O, Unal M, Turan A, Kati Y A and Guler F 2020 Comparison of magnesium versus titanium screw fixation for biplane chevron medial malleolar osteotomy in the treatment of osteochondral lesions of the talus Eur. J. Orthop. Surg. Traumatol. 30 163-73

[25] Atkinson H D, Khan S, Lashgari Y and Ziegler A 2019 Hallux valgus correction utilising a modified short scarf osteotomy with a magnesium biodegradable or titanium compression screws-a comparative study of clinical outcomes $B M C$ Musculoskelet. Disorders 20334

[26] Angrisani N, Reifenrath J, Zimmermann F, Eifler R, Meyer-Lindenberg A, Vano-Herrera K and Vogt C 2016 Biocompatibility and degradation of LAE442-based magnesium alloys after implantation of up to 3.5 years in a rabbit model Acta Biomater. 44 355-65

[27] Krause A, von der Höh N, Bormann D, Krause C, Bach F-W, Windhagen $\mathrm{H}$ and Meyer-Lindenberg A 2010 Degradation behaviour and mechanical properties of magnesium implants in rabbit tibiae J. Mater. Sci. 45 624-32

[28] Thomann M, Krause C, Bormann D, von der Höh N, Windhagen $\mathrm{H}$ and Meyer-Lindenberg A 2009 Comparison of the resorbable magnesium alloys LAE442 und $\mathrm{MgCa}_{0.8}$ concerning their mechanical properties, their progress of degradation and the bone-implant-contact after 12 months implantation duration in a rabbit model Materwiss. Werksttech. 40 82-7

[29] Witte F, Fischer J, Nellesen J, Vogt C, Vogt J, Donath T and Beckmann F 2010 In vivo corrosion and corrosion protection of magnesium alloy LAE442 Acta Biomater. 6 1792-9

[30] Ullmann B, Reifenrath J, Seitz J M, Bormann D and Meyer-Lindenberg A 2013 Influence of the grain size on the in vivo degradation behaviour of the magnesium alloy LAE442 Proc. Inst. Mech. Eng. H 227 317-26

[31] Hampp C, Angrisani N, Reifenrath J, Bormann D, Seitz J M and Meyer-Lindenberg A 2013 Evaluation of the biocompatibility of two magnesium alloys as degradable implant materials in comparison to titanium as non-resorbable material in the rabbit Mater. Sci. Eng. C 33 317-26

[32] Weizbauer A, Seitz J M, Werle P, Hegermann J, Willbold E, Eifler R, Windhagen H, Reifenrath J and Waizy H 2014 Novel magnesium alloy $\mathrm{Mg}-2 \mathrm{La}$ caused no cytotoxic effects on cells in physiological conditions Mater. Sci. Eng. C 41 267-73

[33] Lalk M, Reifenrath J, Angrisani N, Bondarenko A, Seitz J M, Mueller P P and Meyer-Lindenberg A 2013 Fluoride and calcium-phosphate coated sponges of the magnesium alloy AX30 as bone grafts: a comparative study in rabbits J. Mater. Sci. Mater. Med. 24 417-36
[34] Fischerauer S F, Kraus T, Wu X, Tangl S, Sorantin E, Hanzi A C, Loffler J F, Uggowitzer P J and Weinberg A M 2013 In vivo degradation performance of micro-arc-oxidized magnesium implants: a micro-CT study in rats Acta Biomater. 9 5411-20

[35] Thomann M, Krause C, Angrisani N, Bormann D, Hassel T, Windhagen $\mathrm{H}$ and Meyer-Lindenberg A 2010 Influence of a magnesium-fluoride coating of magnesium-based implants (MgCa0.8) on degradation in a rabbit model J. Biomed. Mater. Res. A 93 1609-19

[36] Yu W et al 2017 In vitro and in vivo evaluation of $\mathrm{MgF}_{2}$ coated AZ31 magnesium alloy porous scaffolds for bone regeneration Colloids Surf. B 149 330-40

[37] Zhao N, Workman B and Zhu D 2014 Endothelialization of novel magnesium-rare earth alloys with fluoride and collagen coating Int. J. Mol. Sci. 15 5263-76

[38] Li Z, Shizhao S, Chen M, Fahlman B D, Debao L and Bi H 2017 In vitro and in vivo corrosion, mechanical properties and biocompatibility evaluation of $\mathrm{MgF}_{2}$-coated $\mathrm{Mg}-\mathrm{Zn}-\mathrm{Zr}$ alloy as cancellous screws Mater. Sci. Eng. C 75 1268-80

[39] Seyedraoufi Z S and Mirdamadi S 2013 Synthesis, microstructure and mechanical properties of porous $\mathrm{Mg}-\mathrm{Zn}$ scaffolds J. Mech. Behav. Biomed. Mater. 21 1-8

[40] Witte F, Ulrich H, Palm C and Willbold E 2007 Biodegradable magnesium scaffolds: part II: peri-implant bone remodeling J. Biomed. Mater. Res. A 81 757-65

[41] Julmi S, A-k K, Waselau A-C, Meyer-Lindenberg A, Wriggers P, Klose C and Maier H J 2019 Processing and coating of open-pored absorbable magnesium-based bone implants Mater. Sci. Eng. C 98 1073-86

[42] Julmi S, Klose C, Krüger A-K, Wriggers P and Maier H J 2017 Development of sponge structure and casting conditions for absorbable magnesium bone implants TMS 2017 146th Annual Meeting \& Exhibition Supplemental Proc. (Springer, Cha) pp 307-17

[43] Kleer N, Julmi S, Gartzke A-K, Augustin J, Feichtner F, Waselau A-C, Klose C, Maier H, Wriggers P and Meyer-Lindenberg A J M 2019 Comparison of degradation behaviour and osseointegration of the two magnesium scaffolds, LAE442 and La2, in vivo Materialia 8100436

[44] Lalk M, Reifenrath J, Rittershaus D, Bormann D and Meyer-Lindenberg A 2010 Biocompatibility and degradation behaviour of degradable magnesium sponges coated with bioglass - method establishment within the framework of a pilot study Materwiss. Werksttech. 41 1025-34

[45] Donath K and Breuner G 1982 A method for the study of undecalcified bones and teeth with attached soft tissues. The Sage-Schliff (sawing and grinding) technique J. Oral Pathol. $11318-26$

[46] Huehnerschulte T A, Reifenrath J, von Rechenberg B, Dziuba D, Seitz J M, Bormann D, Windhagen H and Meyer-Lindenberg A 2012 In vivo assessment of the host reactions to the biodegradation of the two novel magnesium alloys ZEK100 and AX30 in an animal model Biomed. Eng. Online 1114

[47] Cheng M Q, Wahafu T, Jiang G F, Liu W, Qiao Y Q, Peng X C, Cheng T, Zhang X L, He G and Liu X Y 2016 A novel open-porous magnesium scaffold with controllable microstructures and properties for bone regeneration Sci. Rep. 624134

[48] Mousny M, Omelon S, Wise L, Everett E T, Dumitriu M, Holmyard D P, Banse X, Devogelaer J P and Grynpas M D 2008 Fluoride effects on bone formation and mineralization are influenced by genetics Bone 43 1067-74

[49] Hampp C, Ullmann B, Reifenrath J, Angrisani N, Dziuba D, Bormann D, Seitz J M and Meyer-Lindenberg A 2012 Research on the biocompatibility of the new magnesium alloy LANd442 - an in vivo study in the rabbit tibia over 26 weeks Adv. Eng. Mater. 14 B28-B37

[50] Erdmann N, Angrisani N, Reifenrath J, Lucas A, Thorey F, Bormann D and Meyer-Lindenberg A 2011 Biomechanical testing and degradation analysis of $\mathrm{MgCa}_{0.8}$ alloy screws: $\mathrm{a}$ comparative in vivo study in rabbits Acta Biomater. 7 1421-8 
[51] Jansen J A, Dhert W J, van der Waerden J P and von Recum A F 1994 Semi-quantitative and qualitative histologic analysis method for the evaluation of implant biocompatibility J. Invest. Surg. 7 123-34

[52] Hofmann S et al 2013 Remodeling of tissue-engineered bone structures in vivo Eur. J. Pharm. Biopharm. 85 119-29

[53] von der Höh N, Bormann D, Lucas A, Denkena B, Hackenbroich C and Meyer-Lindenberg A 2009 Influence of different surface machining treatments of magnesium-based resorbable implants on the degradation behavior in rabbits $J$. Adv. Eng. Mater. 11 B47-B54

[54] Rossig C, Angrisani N, Helmecke P, Besdo S, Seitz J M, Welke B, Fedchenko N, Kock H and Reifenrath J 2015 In vivo evaluation of a magnesium-based degradable intramedullary nailing system in a sheep model Acta Biomater. 25 369-83

[55] Payr E 1900 Beiträge zur Technik der Blutgefäss-und Nervennaht nebst Mittheilungen über die Verwendung eines resorbirbaren Metalles in der Chirurgie Arch. Klin. Chir. 62 67-93

[56] Kraus T et al 2014 Biodegradable Fe-based alloys for use in osteosynthesis: outcome of an in vivo study after 52 weeks Acta Biomater. $103346-53$

[57] Kraus T, Fischerauer S, Treichler S, Martinelli E, Eichler J, Myrissa A, Zotsch S, Uggowitzer P J, Loffler J F and Weinberg A M 2018 The influence of biodegradable magnesium implants on the growth plate Acta Biomater. 66 109-17
[58] Sedman A B, Alfrey A C, Miller N L and Goodman W G 1987 Tissue and cellular basis for impaired bone formation in aluminum-related osteomalacia in the pig J. Clin. Invest. 79 86-92

[59] Talwar H S, Reddi A H, Menczel J, Thomas W C Jr and Meyer J L 1986 Influence of aluminum on mineralization during matrix-induced bone development Kidney Int. 29 1038-42

[60] Quarles L D, Dennis V W, Gitelman H J, Harrelson J M and Drezner M K 1985 Aluminum deposition at the osteoid-bone interface. An epiphenomenon of the osteomalacic state in vitamin D-deficient dogs J. Clin. Invest. 75 1441-7

[61] Li W P, Ma D S, Higginbotham C, Hoffman T, Ketring A R, Cutler C S and Jurisson S S 2001 Development of an in vitro model for assessing the in vivo stability of lanthanide chelates Nucl. Med. Biol. 28 145-54

[62] Southwick F S, Li W, Zhang F, Zeile W L and Purich D L 2003 Actin-based endosome and phagosome rocketing in macrophages: activation by the secretagogue antagonists lanthanum and zinc Cell Motil. Cytoskeleton 54 41-55

[63] Feyerabend F, Siemers C, Willumeit R and Rosler J 2009 Cytocompatibility of a free machining titanium alloy containing lanthanum J. Biomed. Mater. Res. A 90 931-9

[64] von der Höh N, von Rechenberg B, Bormann D, Lucas A and Meyer-Lindenberg A 2009 Influence of different surface machining treatments of resorbable magnesium alloy implants on degradation-EDX-analysis and histology results Mat.-wiss. Werkstofftech. 40 88-93 